Canadian Journal of Fisheries and Aquatic Sciences

Canadian Science Publishing

Journal canadien des sciences halieutiques et aquatiques

\title{
Exploring optimal walleye exploitation rates for northern Wisconsin Ceded Territory lakes using a hierarchical Bayesian age-structured model
}

\begin{tabular}{|r|l|}
\hline Journal: & Canadian Journal of Fisheries and Aquatic Sciences \\
\hline Manuscript ID & cjfas-2015-0191.R2 \\
\hline Manuscript Type: & Article \\
\hline Complete List of Authors: & $\begin{array}{l}\text { Tsehaye, Iyob; Michigan State University, Quantitative Fisheries Center } \\
\text { Roth, Brian; Michigan State University, } \\
\text { Sass, Greg; Wisconsin Department of Natural Resources, Escanaba Lake } \\
\text { Research Station }\end{array}$ \\
\hline Keyword: & $\begin{array}{l}\text { FISHERY MANAGEMENT < General, POPULATION DYNAMICS < General, } \\
\text { LAKES < Environment/Habitat, BAYESIAN STATISTICS < General, } \\
\text { WISCONSIN WALLEYE }\end{array}$ \\
\hline \multicolumn{2}{|c}{} \\
\hline
\end{tabular}

SCHOLARONE

Manuscripts 
1 Exploring optimal walleye exploitation rates for northern Wisconsin Ceded

2 Territory lakes using a hierarchical Bayesian age-structured model

3 Iyob Tsehaye ${ }^{1 * \dagger}$, Brian M. Roth ${ }^{2}$, and Greg G. Sass ${ }^{3}$

$4{ }^{1}$ Quantitative Fisheries Center, Department of Fisheries and Wildlife, Michigan State University,

5293 Farm Lane, Room 153, East Lansing, MI, 48824, USA

$6 \quad{ }^{2}$ Department of Fisheries and Wildlife, Michigan State University, 480 Wilson Road, Room 13,

7 East Lansing, MI, 48824, USA

$8 \quad{ }^{3}$ Escanaba Lake Research Station, Wisconsin Department of Natural Resources, 3110 Trout Lake

9 Station Drive, Boulder Junction, WI 54512, USA

$10{ }^{*}$ Corresponding author: tsehaye@msu.edu, iyob.tsehaye@wisconsin.gov

11 'Present address: Wisconsin Department of Natural Resources, Science Services, 2801 Progress

12 Road, Madison, WI 53716, USA 


\section{Abstract}

15 We assessed population dynamics of walleye (Sander vitreus) in multiple Ceded Territory lakes,

16 supporting recreational and tribal fisheries, using a hierarchical Bayesian age-structured model.

17 We used distributions of parameter estimates to develop a dynamic simulation model to forecast

18 performances of walleye fisheries across these lakes under alternative recreational and tribal

19 fishing scenarios. Application of a hierarchical approach allowed us to obtain more accurate

20 estimates of stock-recruitment relationships, natural mortality, maturity and selectivity

21 schedules, and growth parameters for individual lakes, especially for those with relatively

22 uninformative data, and to characterize their variability among lakes. Using standing spawning

23 stock biomass, recreational and tribal harvest, and probability of population collapse as

24 performance metrics, our simulations suggest that northern Wisconsin walleye populations can

25 sustain a regional optimal exploitation rate of about $20 \%$ on average given the existing

26 recreational and tribal gear selectivities. However, lake-specific optimal exploitation rates may

27 be higher or lower depending on estimated lake productivities, suggesting that effective

28 management of the Ceded Territory walleye fisheries should account for variability in population

29 dynamics among lakes. 


\section{Introduction}

Sustainability of walleye (Sander vitreus) populations in northern Wisconsin Ceded

33 Territory lakes has been an issue of concern to fisheries managers since off-reservation tribal

34 hunting, fishing, and gathering rights were affirmed to Lake Superior Chippewa tribes.

35 Consequently, these populations have been subjected to recreational (angling) and tribal

36 (spearing) exploitation (Hansen et al. 1991; Schueller et al. 2008; Cichosz 2012). This multi-user

37 fishery has been managed by setting total allowable catches (TAC) to not exceed, in not more

38 than 1 in 40 occasions, an annual adult exploitation rate of $35 \%$, which is presumed to ensure

39 optimal sustainable yields for the walleye populations (Staggs et al. 1990). These TACs are

40 implemented through lake-specific spearing quotas and angler bag and minimum length limits

41 agreed upon between the Wisconsin Department of Natural Resources (WDNR) and the Great

42 Lakes Indian Fish and Wildlife Commission (GLIFWC). Annual TAC quotas for individual

43 lakes are established based on lake-specific adult density estimates from mark-recapture surveys

44 or by using empirical relationships relating adult walleye abundance to lake area when

45 population estimates are not available or deemed outdated (Staggs et al. 1990; Hansen et al.

46 1991; Nate et al. 2001). Mark-recapture surveys conducted on 29 northern Wisconsin lakes in

472010 showed that adult walleye densities ranged from 0.8 to $21.8 \mathrm{fish} \cdot \mathrm{ha}^{-1}$ (Cichosz 2012), and a

48 log-linear lake area-adult walleye abundance regression suggested that average regional density

49 for northern Wisconsin lakes is about $8.9 \mathrm{fish} \cdot \mathrm{ha}^{-1}(95 \%$ confidence interval $=2.92-26.71$

50 fish $\left.\cdot h^{-1}\right)($ Schueller et al. 2008).

51 Maximum TAC for all northern Wisconsin lakes has been set at $35 \%$ of adult abundance,

52 apparently based on an implicit assumption that all lakes are equally productive. However,

53 optimal fishery yields may vary from lake to lake depending on the balance between mortality 
54 and recruitment dynamics of individual populations, with the maximum reproductive rate at low

55 stock size determining the biological limits of fishing (Myers et al. 1999; Gibson and Myers

56 2003). Therefore, accounting for variability in walleye productivity among lakes is important

57 because managing fisheries in all lakes as though they are equally productive may be suboptimal

58 if this leads to overexploitation of some populations. Indeed, several studies have been

59 conducted to assess the potential for walleye fisheries across northern Wisconsin lakes. For

60 example, walleye recruitment variability was related to density-dependent and -independent

61 factors, including temperature and competition with or predation by adult yellow perch (Perca

62 flavescens), in Escanaba Lake (Hansen et al.1998) and across multiple northern Wisconsin lakes

63 (Beard et al.2003a; Hansen et al. 2015). Schueller et al. (2008) evaluated the sustainability of

64 walleye populations in northern Wisconsin across a range of initial densities using an age-

65 structured simulation model based on estimates of walleye stock recruitment relationship in

66 Escanaba Lake. Accordingly, walleye populations in northern Wisconsin were determined to

67 support sustainable exploitation rates of 60-85\% depending on allocations of angling and

68 spearing harvest and minimum length limits for recreational fisheries. However, these

69 exploitation rates were identified based on probabilities of extinction or population decline, and

70 thus are not necessarily optimal. More recently, Hansen et al. (2011) assessed changes in walleye

71 natural mortality in relation to fishing mortality and fish abundance using an age-structured

72 population model. In addition to these studies focusing on walleye population dynamics, several

73 whole-lake experiments have been conducted in northern Wisconsin to directly evaluate

74 population responses to sustained exploitation rates. Specifically, Big Crooked and Sherman

75 lakes were experimentally subjected to ten-year walleye exploitation rates of 35 and $50 \%$,

76 respectively, which led to declines in adult walleye densities and changes in growth and 
77 maturation schedules in both lakes (U.S. Department of the Interior 1991; Schueller et al. 2005;

78 Schmalz et al. 2011). Although previous studies have led to a better understanding of the status

79 and dynamics of walleye populations in northern Wisconsin lakes, they have not covered the

80 entire range of walleye productivity in the Ceded Territory because they focused on a few

81 selected lakes with the best data available. As a result, patterns in walleye productivity in

82 northern Wisconsin lakes remained to be investigated, which is essentially a prerequisite for the

83 development of an effective fishing policy.

84 Relatively large amount of walleye demographic data are available for many northern

85 Wisconsin lakes. However, many of the time-series data are still not informative enough to

86 reliably assess population dynamics or long enough to provide sufficient contrast to accurately

87 estimate stock-recruitment relationships for individual lakes. Under such circumstances,

88 hierarchical Bayesian meta-analysis can be a useful method for improving assessment of walleye

89 population dynamics across northern Wisconsin lakes, considering that these lakes likely possess

90 biological and environmental similarities and are subjected to a joint fishery. Rather than simply

91 pooling data, hierarchical Bayesian models assume an underlying probability distribution for

92 parameters of interest that is common to all populations (i.e., the prior distribution) (Myers et al.

93 1999; Maunder 2003; Gelman et al. 2004). By analyzing data from multiple, related populations

94 simultaneously, and thus allowing data sets with little information about parameters to borrow

95 information from other data sets, hierarchical meta-analysis has the advantage of providing more

96 accurate parameter estimates for populations with uninformative data (Gelman et al. 2004;

97 Forrest et al. 2010). As such, hierarchical Bayesian analysis of walleye demographic data sets

98 from the northern Wisconsin lakes could be used to obtain more accurate estimates of population

99 parameters for individual lakes and to characterize their variability among these lakes. 
Several previous studies have applied hierarchical Bayesian methods to assess population

101 and fishery processes, including stock-recruitment relationships (Chen and Holtby 2002, Forrest

102 et al. 2010, Su and Peterman 2012), growth of fish (Pilling et al. 2002; He and Bence 2007; He et

103 al. 2008), and other specific aspects of fishery or population dynamics (e.g., catchability,

104 intrinsic rate of population growth) (Meyer and Millar 1999, Millar and Methot 2002, Tsehaye et

105 al. 2013). However, these studies either did not fully describe population dynamics or were

106 based on simplified population models (such as the surplus production model), in large part due

107 to the specific type of data available for these studies. In contrast, we were able to conduct a

108 more comprehensive analysis of walleye population dynamics to estimate a whole set of

109 population and fishery parameters because multiple types of fishery-dependent and -independent

110 data were available for many of the northern Wisconsin lakes. Lake-specific data sets available

111 included time-series of adult walleye abundances and age composition, age-0 walleye

112 abundances, length-at-age, angling and spearing exploitation rates, and length composition of

113 spearing harvest. The availability of such information allowed us to estimate stock-recruitment

114 relationships, natural mortalities, maturity and selectivity schedules, and growth parameters for

115 multiple lakes. Based on estimates of demographic parameters and associated uncertainties, we

116 then developed a forecasting model to evaluate performances of the walleye fisheries regionally

117 and in individual lakes under different exploitation rates and allocations of angling and spearing

118 harvest. Our ultimate goal was to determine optimal walleye harvest policies (providing the

119 largest sustainable harvest $\cdot \mathrm{ha}^{-1}$ ) for the northern Wisconsin Ceded Territory lakes.

121 Methods

122 Study area and the management system 
124 (mostly $<400$ ha), over 900 of which support walleye populations (Beard et al. 2003a; Cichosz 125 2012) (Fig. 1). The Ceded Territory contains 77\% of Wisconsin's lakes, accounting for 53\% of 126 the total inland lake surface area in Wisconsin (Staggs et al. 1990). Walleye fisheries in some of 127 these lakes are supported by stocking, while the fisheries in the majority of these lakes are 128 sustained by natural reproduction (Nate et al. 2000). Recreational and tribal walleye fisheries in 129 the Ceded Territory are managed using a "safe harvest" quota system, wherein the maximum 130 acceptable risk of exploitation rates exceeding 35\% is 1 in 40 occasions (Staggs et al. 1990; 131 Hansen et al. 1991), i.e., given average adult densities and associated measures of error (see 132 below). Under this management system, the tribes annually declare their target (percent) harvest 133 for off-reservation lakes, and the WDNR then sets annual recreational angler bag limits $(\leq 5$ 134 walleye $\cdot$ day $^{-1}$ ) such that total exploitation rate does not exceed $35 \%$ by increasing or lowering 135 angling bag limits in response to tribal harvest each year, commonly known as a sliding bag limit 136 system (Beard et al. 2003b).

137 As part of the walleye fishery management system, the WDNR and GLIFWC have 138 monitored the status and trends of walleye populations in northern Wisconsin lakes since 1987 139 (Cichosz 2012). The status of walleye populations in these lakes have been evaluated using (a) 140 mark-recapture experiments, to obtain spring adult population estimates (PEs) (expressed as 141 means and associated coefficients of variation (CVs) based on repeated random samples), (b) 142 electrofishing, to estimate fall age-0 (young-of-year) catch per effort (CPE) and abundance, and 143 (c) creel surveys/census, to estimate/enumerate recreational/tribal harvest and effort (Cichosz 144 2012). In the WDNR mark-recapture experiments, fyke nets are used to capture adult walleyes 145 for marking, and AC electrofishing is used to recapture walleyes (Hansen et al. 2000; Beard et al. 
146 2003b). Mark-recapture surveys by the GLIFWC use pulsed-DC electrofishing to catch and

147 recapture walleye. Adult age composition in these surveys has been determined based on fish

148 aging using scales (for smaller fish) and dorsal fin spines (for larger fish). In addition, length-at-

149 age data have been recorded for individual lakes. In this study, we selected 25 lakes from the

150 Ceded Territory with age-specific adult PEs and five or more years of data on adult PEs and age-

1510 abundance, which we assumed to provide sufficient contrast to analyze stock-recruitment

152 relationships and other population dynamics.

\section{Population dynamics and parameter estimation}

155 We assessed stock-recruitment relationships and other walleye population dynamics in

156 two separate steps, described in separate sections below. Traditionally, stock recruitment analysis

157 has been performed after time-series of spawning stock and recruitment have been estimated

158 using another assessment model, typically based on fishery-dependent catch, age composition

159 and effort data. Intuitively, it would be more appropriate to analyze the stock-recruitment

160 relationship inside the stock assessment model because the analysis will automatically

161 incorporate the uncertainty in stock and recruitment estimates into the stock-recruitment

162 parameter estimates (Maunder and Punt, 2013). Yet, several recent simulation studies have

163 shown that the estimates of the stock-recruitment relationship are actually often highly uncertain

164 or biased (Magnusson and Hilborn 2007, Conn et al. 2010, Lee et al. 2012, Maunder and Piner

165 2015). Either way, the availability of direct fishery-independent estimates of walleye recruit and

166 spawning stock abundances for the Ceded Territory lakes from annual electrofishing and mark-

167 recapture surveys avoided the need for us to rely on model estimated stock and recruit

168 abundances. 
In a subsequent step, parameter estimates from the two assessments were used as inputs

170 to build a forecasting model to simulate walleye population responses to fishing. Definitions of

171 parameters and variables used in walleye estimation and simulation models are given in Table 1.

172 The numbers of years of data of adult and age- 0 abundance available for each of the selected

173 lakes is shown in Table 2, with Escanaba Lake having the longest time-series data.

\section{Stock-recruitment relationships}

We assessed stock-recruitment relationships regionally and in individual lakes by fitting

177 Ricker models to time series of spawner-recruit data from the 25 lakes assumed to have a

178 sufficient number of years of data on adult and age- 0 abundance. For spawners, we used the

179 spring adult PEs. Age-0 walleye abundances $\left(N_{0}\right)$ were calculated from electrofishing CPEs

180 using a relationship developed by Hansen et al. (2004):

$$
N_{0}=0.0345 * C P E^{1.564}
$$

182 We fit stock-recruitment relationships to individual lakes simultaneously using a hierarchical 183 model:

$$
\begin{array}{ll}
R_{i, t}=\alpha_{i} S_{i, t} e^{-\beta_{i} S_{i, t}} & \\
\hat{R}_{i, t}=R_{i, t} e^{\omega_{i, t}}, & \omega_{i, t} \sim N\left(0, \sigma_{\mathrm{R}, i}^{2}\right), \\
\hat{S}_{i, t}=S_{i, t} e^{v_{i, t}}, & v_{i, t} \sim N\left(0, \sigma_{\mathrm{S}, i}^{2}\right),
\end{array}
$$

187 where annual recruitment $\left(R_{i, t}\right)$ is predicted for each lake $(i)$ by year $(t)$, with observed

188 recruitments being $\hat{R}$. The deviations $\omega_{i, t}$ combine both measurement error, representing the

189 difference between measured and actual recruitment, and process error, representing deviations

190 from the direct proportionality assumption between stock and recruitment (i.e., according to the 
191 stock-recruitment relationship) or inter-annual variability in recruitment. Similarly, considering

192 that we do not observe spawning stock size directly, observed spawning stock size $\hat{S}_{i, t}$ was

193 expressed as a function of actual spawning stock size $S_{i, t}$ estimated as parameters by accounting

194 for measurement error $v_{i, t} ; \sigma_{\mathrm{S}, i}$ values were calculated externally based on the CVs (Evans et al.

195 2000) of adult PEs from the mark-recapture experiments described above (resulting in $\sigma_{\mathrm{S}, i}=$

196 0.06-0.18). By accounting for both measurement and process errors, our model provided - in

197 effect - a state-space representation of walleye recruitment dynamics.

198 In our base hierarchical model, stock-recruitment parameters were assumed to vary

199 among lakes following a normal or lognormal distribution, with central tendency parameters $\bar{\alpha}$,

$200 \bar{\beta}$, and $\overline{\sigma_{\mathrm{R}}}$ and multiplicative and additive process errors $\varepsilon_{\alpha, i}$, and $\varepsilon_{\beta, i}$, respectively (eq. 3). $\varepsilon_{\alpha, i}$

201 and $\varepsilon_{\beta, i}$ were assumed to be correlated and follow a bivariate normal distribution with a vector

202 of means $\underline{0}$ and variance-covariance matrix $\sum$; thus, $\alpha_{i}$ and $\beta_{i}$ would follow a bivariate

203 lognormal-normal (LNN) distribution. $\sigma_{\mathrm{R}, i}^{2}$ was assumed to follow an inverse-gamma

204 distribution. We selected a model with LNN prior for $\alpha_{i}$ and $\beta_{i}$ and inverse-gamma prior for $\sigma_{\mathrm{R}, i}^{2}$

205 as the best (base) model among alternative models based on deviance information criterion

206 (DIC) (see section Model sensitivity to prior assumptions). In fact, the inverse-gamma

207 distribution is commonly used as a prior for variance (Gelman et al., 2004). Thus,

208

$$
\begin{aligned}
& \alpha_{i}=\bar{\alpha} e^{\varepsilon_{\alpha, i}}, \\
& \beta_{i}=\bar{\beta}+\varepsilon_{\beta, i}, \\
& {\left[\begin{array}{l}
\varepsilon_{\alpha, i} \\
\varepsilon_{\beta, i}
\end{array}\right] \sim N\left(\left[\begin{array}{l}
0 \\
0
\end{array}\right], \Sigma_{\varepsilon}\right),}
\end{aligned}
$$

209

210 


$$
\sigma_{\mathrm{R}, i}^{2} \sim \operatorname{Inv}-\operatorname{gamma}\left(\alpha^{\prime}, \beta^{\prime}\right)
$$

212 where, the parameters (including process errors or random effects) $\bar{\alpha}, \bar{\beta}, \varepsilon_{\alpha, i}, \varepsilon_{\beta, i}$, and $\sigma_{\mathrm{R}, i}^{2}$

213 were estimated as first-level parameters; $\Sigma_{\varepsilon}, \alpha^{\prime}$, and $\beta^{\prime}$ were estimated as second-level

214 parameters (also known as hyperparameters). $\Sigma_{\varepsilon}$ was estimated through Cholesky decomposition

215 as a function of the standard deviations of $\varepsilon_{\alpha, i}$, and $\varepsilon_{\beta, i}$ and an "off diagonal" parameter defining

216 the correlation between the two (ADMB Project 2013). The expected (regional) $\overline{\sigma_{\mathrm{R}}^{2}}$ was

217 calculated as a derived variable as a function of the shape $\left(\alpha^{\prime}\right)$ and scale $\left(\beta^{\prime}\right)$ parameters as

$218 \frac{\beta^{\prime}}{\alpha^{\prime}-1}$

219 We used a Bayesian approach for model fitting and to characterize uncertainty of

220 parameter estimates. For our hierarchical Bayesian model, the joint posterior probability

221 distribution for the unknown parameters and hyperparamters can be specified as

$$
P(\theta, \varepsilon, \phi \mid \mathrm{X}) \propto L(\mathrm{X} \mid \theta, \varepsilon) P(\varepsilon \mid \phi) P(\theta) P(\phi)
$$

223 where $L(\mathrm{X} \mid \theta, \varepsilon)$ represents data likelihoods, $P(\varepsilon \mid \phi)$ and $P(\theta)$ prior probability distributions

224 for the first-level parameters ( $\varepsilon$ and $\theta), P(\phi)$ prior probability distributions (also known as

225 hyperpriors) for the hyperparameters $\phi$. For model fitting, we calculated the log of the joint

226 posterior probability as the sum of (1) $\log$-likelihood $(\log L)$ of observed data, (2) $\log$-priors

$227(\log P)$ for first-level parameters and (3) log-hyperpriors for the second-level parameters, defined

228 as follows. Log-likelihoods of observed recruit $\hat{R}$ and stock size $\hat{S}$ data were calculated as

229

$$
\log L=-\sum_{i=1}^{25} \sum_{t}\left[\ln \left(\sigma_{i}\right)+\frac{\left(d e v_{i, t}\right)^{2}}{2 \operatorname{sig}_{i}^{2}}\right]
$$


230 where $d e v_{i, t}$ is $\omega_{i, t}$ or $v_{i, t}$ (i.e., differences between log of predicted and observed $\hat{R}$ or $\hat{S}$ values),

231 and $\operatorname{sig}_{i}$ is $\sigma_{\mathrm{R}, i}$ or $\sigma_{\mathrm{S}, i}$, respectively. Log-prior for the bivariate process errors $\varepsilon_{\alpha, i}$ and $\varepsilon_{\beta, i}$,

232 inverse-gamma log-prior for the first-level parameter $\sigma_{\mathrm{R}, i}^{2}$, and log-prior for the first-level

233 parameters $\bar{\alpha}$ and $\bar{\beta}$ were, respectively, specified as:

$234(6)$

$$
\begin{aligned}
& \log P=-\left(\frac{25}{2}\right) \ln \left|\sum_{\varepsilon}\right|-0.5 \sum_{i=1}^{25}\left[\underline{x}_{i}^{T} \sum_{\varepsilon}{ }^{-1} \underline{x}_{i}\right], \\
& \log P=\sum_{i=1}^{25}\left[\alpha^{\prime} \ln \left(\beta^{\prime}\right)-\ln \left(\Gamma\left(\alpha^{\prime}\right)\right)-\left(\alpha^{\prime}+1\right) \ln \left(\sigma_{\mathrm{R}, i}^{2}\right)-\frac{\beta^{\prime}}{\sigma_{\mathrm{R}, i}^{2}}\right],
\end{aligned}
$$

$$
\log P=-\frac{1}{2}\left[(\underline{x}-\underline{\mu})^{T} \Sigma^{-1}(\underline{x}-\underline{\mu})\right]
$$

237 where the vector $\underline{x}_{i}=\left(\varepsilon_{\alpha, i}, \varepsilon_{\beta, i}\right), \underline{x}=(\bar{\alpha}, \bar{\beta}), \underline{\mu}=(2.5,0.1), \Sigma=\left[\begin{array}{ll}25^{2} 0 \\ 0 & 1^{2}\end{array}\right]$. The values of $\underline{\mu}$ were

238 derived from preliminary analysis based on data likelihoods, and the corresponding standard

239 deviations were assumed to be $10 \times \underline{\mu}$ with the intent for the priors to be only weakly

240 informative so that the data would predominantly determine parameter estimates. Log-

241 hyperpriors for the elements of $\Sigma_{\varepsilon}$ and for $\alpha^{\prime}$ and $\beta^{\prime}$ were specified as

$$
\log P=-0.5\left(\frac{x-\mu}{\sigma}\right)^{2}
$$

243 where $x$ is either the standard deviation of $\varepsilon_{\alpha, i}$ or $\varepsilon_{\beta, i}$; the "off diagonal" parameter for $\Sigma_{\varepsilon}$; or $\alpha$ '

244 or $\beta^{\prime}$. Just as above, the values of $\mu$ were selected based on preliminary analysis of data without 245 hyperpriors, and the values of $\sigma$ were set at $10 \times \mu$.

246 Posterior distributions of parameter estimates were obtained using Markov Chain Monte

247 Carlo (MCMC) sampling. The Metropolis-Hastings algorithm within AD Model Builder 
248 (Fournier et al. 2012) was used to obtain MCMC samples from the joint posterior distribution of

249 parameter estimates. AD Model Builder implementation of MCMC involves first creating an

250 approximate multivariate normal distribution, using the highest posterior density (HPD)

251 estimates as the mode and the inverse of the Hessian at the mode as the variance-covariance

252 matrix (i.e., an asymptotic variance co-variance). HPD parameter estimates were the values

253 obtained when the maximum gradient of the objective function was less than $1.0 \times 10^{-4}$. Using

254 the HPD estimates as starting values, the approximate multivariate normal distribution is then

255 used as a "jumping distribution" for drawing random samples sequentially from the parameter

256 space. At each step, AD Model Builder accepts or rejects the drawn random sample based on the

257 posterior density calculated for the sample, thereby constructing the target posterior distribution

258 (Gelman et al. 2004). The MCMC simulation was run for 1.1 million samples saving every $100^{\text {th }}$

259 sample to produce a total saved sample size of 10,000 after 1,000 samples were discarded as

260 burn-in. MCMC chains were evaluated for adequacy (convergence and sufficient information)

261 using trace plots for each estimated parameter and derived variable, as a visual check to ensure

262 the chain was well-mixed and did not show long-term patterns, the effective sample size, and

263 similarity between the first $10 \%$ and last $50 \%$ of the chain using Geweke's (1992) Z-score test,

264 where $Z<2$ for well mixed chains with no long-term patterns. All MCMC diagnostics were

265 conducted in R (R Development Core Team 2010) using the CODA package (Plummer et al.

266 2010). We summarized posterior distributions of parameters using HPD estimates as point

267 estimates and 95\% Bayesian credible intervals as measure of uncertainty.

268 To determine the extent to which our hierarchical meta-analysis improved (or not) stock-

269 recruitment estimates, we also estimated stock-recruitment relationships independently for

270 individual lakes, in which the stock-recruitment relationship estimated for a given lake would 
271 not account for potential underlying similarities between lakes. For many of these lakes, the

272 time-series spawner-recruit data provided unrealistically high $\alpha$ (e.g., $\alpha=10493.93$ for North

273 Twin lake) or negative $\beta$ (e.g., $\beta=-0.17$ for Squirrel lake) suggesting an exponential increase in

274 recruitment with stock size. Therefore, we excluded these lakes when calculating a regional

275 average stock-recruitment relationship to compare with the regional stock-recruitment

276 relationship from the hierarchical model.

277

278 Model sensitivity to prior assumptions

279 We conducted sensitivity analysis to determine the extent to which our parameter

280 estimates may be influenced by our assumptions of prior distributions. Specifically, this is to test

281 whether our choice of priors in the base model, assuming a bivariate lognormal-normal

282 distribution for $\alpha_{i}$ and $\beta_{i}$ and an inverse-gamma distribution for $\sigma_{\mathrm{R}, i}^{2}$ (referred to as LNN-InvG

283 hereafter), accommodated possible skewness and excess variability among parameters and has

284 not caused over-shrinkage of parameter estimates toward average values. For this purpose, we

285 fitted the hierarchical stock-recruitment model under alternative assumptions of prior

286 distributions for $\alpha_{i}$ and $\beta_{i}$, including a bivariate lognormal-lognormal (LNLN) and a bivariate

287 normal-normal (NN) distributions (referred to as LNLN and NN, respectively, hereafter). For

288 these models, $\sigma_{\mathrm{R}, i}$ was assumed to follow a lognormal distribution, with central tendency

289 parameter $\overline{\sigma_{\mathrm{R}}}$ and multiplicative process error $\varepsilon_{\sigma_{\mathrm{R}, i}}$ :

290

$$
\begin{gathered}
\sigma_{\mathrm{R}, i}=\overline{\sigma_{\mathrm{R}}} e^{\varepsilon_{\sigma_{\mathrm{R}}, i}} \\
\varepsilon_{\sigma_{\mathrm{R}}, i} \sim N\left(0, \sigma_{\sigma_{\mathrm{R}}}^{2}\right)
\end{gathered}
$$


292 Thus, in lieu of the inverse-gamma log-prior for $\sigma_{\mathrm{R}, i}^{2}$ in equation 6 , we specified a $\log$-prior for

293 the process errors $\varepsilon_{\sigma_{\mathrm{R}}, i}$ and the first-level parameter $\bar{\sigma}_{\mathrm{R}}$ as

294

$$
\begin{aligned}
& \log P=-\sum_{i=1}^{25}\left[\ln \left(\sigma_{\sigma_{\mathrm{R}}}\right)+\frac{\varepsilon_{\sigma_{\mathrm{R}}, i}^{2}}{2 \sigma_{\sigma_{\mathrm{R}}}^{2}}\right], \\
& \log P=-0.5\left(\frac{\bar{\sigma}_{\mathrm{R}}-2.0}{20}\right)^{2},
\end{aligned}
$$

and log-hyperprior for the hyperparamter $\sigma_{\sigma_{R}}$ was specified as in equation (7). Additionally, we evaluated an LNLN model with $\sigma_{\mathrm{R}, i}$ assumed to follow an inverse-gamma distribution (referred to as LNLN-InvG hereafter). estimates, we calculated recruitment at unfished equilibrium as an "omnibus" metric summarizing the combined effects on $\alpha_{i}$ and $\beta_{i}$, which was calculated using the 10,000 MCMC

302 samples of parameter estimates as:

303

$$
R_{0}=\frac{\ln (\alpha \mathrm{SPR})}{b \mathrm{SPR}}
$$

304 where SPR was calculated by incorporating natural mortalities and maturity schedules estimated 305 in the next section (Walters and Martell 2004). We assessed similarity between the samples of $R_{0}$ 306 estimates obtained under the different prior assumptions using pairwise Geweke's (1992) Z-score 307 tests, as described above (i.e., between the first $10 \%$ of the chain from the first model and the last $30850 \%$ of the chain from second model). Even if model estimates may not be sensitive to our prior 309 assumptions, we also calculated DIC (Spiegelhalter et al. 2002) to determine which model

310 structure best described our stock-recruit data. The DIC calculations were based on saved 10,000

311 MCMC samples of parameter estimates and associated data likelihoods from MCMC runs 
312 conducted under the various assumptions for prior distributions (Spiegelhalter et al. 2002). DIC

313 was calculated as

$314 \quad(11)$

$$
\mathrm{DIC}=\bar{D}+p_{D}
$$

$$
\bar{D}=\frac{1}{C} \sum_{c=1}^{C}-2 \ln \left(L\left(\text { data } \mid \theta_{c}\right)\right)
$$

$$
p_{D}=\bar{D}-D(\bar{\theta})
$$

Growth, natural mortality, maturity, and selectivity

We conducted an integrated analysis (Maunder 2003) (Fig. 2) to assess natural mortality

320 and maturity and selectivity patterns using a statistical-catch-at-age framework (Deriso et al.

321 1985; Walters and Martell 2004; Fournier et al. 2012), wherein von Bertalanffy (VB) growth

322 functions, logistic maturity and selectivity schedules, and survival curves were fit simultaneously

323 to obtain values to match observed length-at-age of fish and age composition of adult PEs.

324 Because there were many gaps in the time-series of adult PEs for many of the lakes and our goal

325 was to obtain average mortality for use as input to our forecasting model (see section Forecasting

326 model), we pooled annual adult PEs to obtain an average adult age composition for each lake to

327 which a survival curve was fit. Given that there is no evidence that mortality has changed

328 considerably over time, we believe our use of a pooled age distribution is reasonable. We

329 estimated regional and lake-specific growth, maturity parameters, and natural mortality by fitting

330 hierarchical Bayesian models to length-at-age and age composition data from the selected 25

331 lakes, with lake-specific parameters treated as random effects. Growth parameters were

332 estimated by fitting the VB growth function to length-at-age data as

333

$$
L_{i, a}=L_{\infty, i}\left(1-e^{-K_{i}\left(a-t_{0, i}\right)}\right)
$$




$$
L_{i, a, j}=L_{i, a} e^{\xi_{i, a, j}}, \quad \xi_{i, a, j} \sim N\left(0, \sigma_{\mathrm{L}, i}^{2}\right)
$$

335 where $\xi$ is random error representing individual variation in length-at-age with mean 0 and lake336 specific standard deviation $\sigma_{\mathrm{L}, i}$. We assumed that the VB growth parameters varied among lakes

337 following a lognormal distribution, with central tendencies $\overline{L_{\infty}}, \bar{K}, \overline{t_{0}}$, and $\overline{\sigma_{\mathrm{L}}}$ and multiplicative 338 process errors $\varepsilon_{\mathrm{L}_{\infty}, i}, \varepsilon_{\mathrm{K}, i}, \varepsilon_{\mathrm{t}_{0}, i}$, and $\varepsilon_{\sigma_{\mathrm{L}}, i}$ with standard deviations $\sigma_{\mathrm{L}_{\infty}}, \sigma_{\mathrm{k}}, \sigma_{\mathrm{t}_{0}}$, and $\sigma_{\sigma_{\mathrm{L}}}$, 339 respectively, i.e.,

$$
L_{\infty, i}=\overline{L_{\infty}} e^{\varepsilon_{\mathrm{L}_{\infty}, i}}, \quad \varepsilon_{\mathrm{L}_{\infty}, i} \sim N\left(0, \sigma_{\mathrm{L}_{\infty}}^{2}\right)
$$

Thus, $\overline{L_{\infty}}, \bar{K}, \overline{t_{0}}, \overline{\sigma_{\mathrm{L}}}, \varepsilon_{\mathrm{L}_{\infty}, i}, \varepsilon_{\mathrm{K}, i}, \varepsilon_{\mathrm{t}_{0}, i}$, and $\varepsilon_{\sigma_{\mathrm{L}}, i}$ were estimated as first-level parameters, and $\sigma_{\mathrm{L}_{\infty}}$, $\sigma_{\mathrm{K}}, \sigma_{\mathrm{t}_{0}}$, and $\sigma_{\sigma_{\mathrm{L}}}$ were estimated as second-level parameters or hyperparameters.

347 composition of adult PEs. Age composition of spearing harvest closely matched age composition 348 of adults PEs, so we assumed that spearing selectivity was the same as the walleye maturity 349 schedule:

$$
V_{i, a}^{\text {spear }}=\frac{1}{1+\exp \left(-h_{i}\left(a-m_{i}\right)\right)}
$$

351 where $h$ and $m$ were estimated for each lake as random effects parameters. We assumed that $h$ 352 and $m$ varied among lakes following a lognormal distribution, with central tendencies $\bar{h}$ and 
$353 \bar{m}$ and multiplicative process errors $\varepsilon_{\mathrm{h}, i}$ and $\varepsilon_{\mathrm{m}, i}$ for which the standard deviations were $\sigma_{\mathrm{h}}$

354 and $\sigma_{\mathrm{m}}$, respectively.

$$
m_{i}=\bar{m} e^{\varepsilon_{\mathrm{m}, i}} \quad \varepsilon_{\mathrm{m}, i} \sim N\left(0, \sigma_{\mathrm{m}}^{2}\right)
$$

357 As with the stock-recruitment model above, the prior distributions for VB and maturity

358 parameters were selected based on DIC comparisons. Here, we considered different

359 combinations of normal and lognormal prior error distributions for the different parameters.

360 No length/age composition data were available to estimate vulnerability for the

361 recreational fisheries, but Myers et al. (2014) showed that smaller walleyes were not targeted by

362 the recreational walleye fishery in Escanaba Lake. Because minimum length limits are

363 commonly used for the recreational fishery, we used a knife-age selectivity function for this

364 fishery, i.e.,

$$
V_{i, a}^{\mathrm{rec}}= \begin{cases}0, & \text { if } L_{i, a}<38 \mathrm{~cm} \\ 1, & \text { otherwise }\end{cases}
$$

366 where the length corresponding to each age is predicted by the VB growth function for each lake.

367 Subsequently, fishing mortality was calculated as:

368

$$
F_{i, a}=-\ln \left(1-u_{\mathrm{s}, i} V_{i, a}^{\mathrm{spear}}-u_{\mathrm{r}, i} V_{i, a}^{\mathrm{rec}}\right)
$$

369 where $u_{\mathrm{s} . i}$ and $u_{\mathrm{r}, i}$ are averages of annual spearing and recreational exploitation rates,

370 respectively, recorded for each lake. Total mortality $(Z)$ was then calculated as the sum of natural

371 and fishing mortality:

$372 \quad(18)$

$$
Z_{i, a}=M_{i, a}+F_{i, a}
$$


373 Given that walleye natural mortality in northern Wisconsin lakes is higher for younger age

374 classes and that our natural mortality estimates were based on adult age composition, we

375 obtained natural mortality estimates for younger age classes ( $<5$ years old) from Hansen et al.

376 (2011). Age-specific natural mortality for younger age classes was approximated as:

$$
M_{a<5}=0.7 e^{-0.114 a}
$$

378 For older age classes, we estimated lake-specific natural mortalities as parameters. Again, we

379 assumed that estimated natural mortality varied among lakes following a lognormal distribution,

380 with a central tendency $\bar{M}$ and a multiplicative process error $\left(\varepsilon_{\mathrm{M}, i}\right)$ with a standard deviation $\sigma_{\mathrm{M}}$.

$$
M_{i, a \geq 5}=\bar{M} e^{\varepsilon_{\mathrm{M}, i}}, \quad \quad \varepsilon_{\mathrm{M}, i} \sim N\left(0, \sigma_{\mathrm{M}}^{2}\right)
$$

Assuming a scaling age- 0 abundance $N_{i, 0}=1$ (it does not really matter what the value

383 of $N_{i, 0}$ is in the calculation of $P_{i, a}$ ), numbers at older ages were predicted as:

$$
N_{i, a+1}=N_{i, a} e^{-Z_{i, a}}
$$

385 Because the probability of maturity at age was assumed to be equal to vulnerability to spear

386 fishing, the age composition of mature fish was then calculated as:

$$
\begin{aligned}
& N_{i, a}^{\mathrm{mat}}=N_{i, a} V_{i, a}^{\mathrm{spear}} \\
& \operatorname{tot} N_{\mathrm{i}}^{\mathrm{mat}}=\sum_{a} N_{i, a}^{\mathrm{mat}} \\
& P_{i, a}=\frac{N_{i, a}^{\mathrm{mat}}}{\operatorname{tot} N_{i}^{\mathrm{mat}}}
\end{aligned}
$$

390 Parameters were estimated by fitting predicted lengths at age $\left(L_{i, a}\right)$ and predicted proportions by 391 age $\left(P_{a, i}\right)$ to observed lengths-at-age $\left(L_{i, a, j}\right)$ and age composition of adult PEs $\left(\hat{P}_{a, i}\right)$. As with the 392 estimation stock-recruitment relationships above, we calculated the log of the posterior 
393 probability as the sum of (1) $\log$-likelihood $(\log L)$ of observed data, (2) $\log$-priors $(\log P)$ for

394 first-level parameters and (3) log-hyperpriors for the second-level parameters. Log-likelihood

$395(\log L)$ of observed length-at-age data was calculated as,

396

$$
\log L=-\sum_{i=1}^{25} \sum_{j}\left[\ln \left(\sigma_{\mathrm{L}, i}\right)+\frac{\left(\ln \left(L_{i, a, j}\right)-\ln \left(L_{i, a}\right)\right)^{2}}{2 \sigma_{\mathrm{L}, i}^{2}}\right]
$$

and log-likelihood of the data on age composition of adult PEs, which was calculated assuming a

398 multinomial distribution as a function of the effective sample size $\left(n_{i}\right)$, observed $(\hat{P})$, and

399 predicted proportions $(P)$ at age was specified as

400

$$
\log L=n_{i} \sum_{i} \sum_{a} \hat{P}_{i, a} \ln P_{i, a}
$$

$$
\log P=-\sum_{i=1}^{25}\left[\ln \left(\sigma^{*}\right)+\frac{\varepsilon_{i}^{* 2}}{2 \sigma_{*}^{2}}\right]
$$

$$
\text { where } \sigma^{*} \text { is } \sigma_{\mathrm{L}_{\infty}}, \sigma_{\mathrm{K}}, \sigma_{\mathrm{t}_{0}}, \sigma_{\sigma_{\mathrm{L}}}, \sigma_{\mathrm{h}}, \sigma_{\mathrm{m}} \text {, or } \sigma_{\mathrm{M}} \text {, and } \varepsilon_{i}^{*} \text { is } \varepsilon_{\mathrm{L}_{\infty}, i}, \varepsilon_{\mathrm{K}, i}, \varepsilon_{\mathrm{t}_{0}, i}, \varepsilon_{\sigma_{\mathrm{L}}, i}, \varepsilon_{\mathrm{h}, i} \text {, }
$$

$404 \varepsilon_{\mathrm{m}, i}$, or $\varepsilon_{\mathrm{M}, i}$. Log-priors for each of the first-level parameters $\left(\overline{L_{\infty}}, \bar{K}, \overline{t_{0}}, \overline{\sigma_{\mathrm{L}}}, \bar{h}, \bar{m}, \bar{M}\right)$ and log-

405 hyperpriors for all second-level parameters $\left(\sigma_{\mathrm{L}_{\infty}}, \sigma_{\mathrm{K}}, \sigma_{\mathrm{t}_{0}}, \sigma_{\mathrm{h}}, \sigma_{\mathrm{m}}\right.$, and $\left.\sigma_{\mathrm{M}}\right)$ were specified the

406 same way as in eq. 7, with parameter values for prior distributions selected based on preliminary 407 analysis of data and standard deviations set at 10 fold the mean values.

408 For the multinomial log-likelihood function, we used the same effective sample size $\left(n_{i}\right)$

409 for all lakes. Effective sample sizes weight the relative importance of likelihood components

410 corresponding to age compositions. The use of effective sample size, rather than actual sample

411 size, is based on the recognition that the number of independent sample units is smaller than the

412 actual number of fish aged due to nonrandomness of samples. However, this issue is not relevant 
413 in our model because the multinomial log-likelihood (for age composition) was the only

414 likelihood function in our integrated analysis (i.e., except for the log-likelihood function for

415 length at age data to fit VB growth functions, which do not have any interactions with the model

416 fits to age compositions). Therefore, parameter estimates are not affected by our choice of

417 effective sample size. Indeed, the relative weightings of likelihood functions (hence the effective

418 sample size) would have been an issue if we had used our integrated analysis to obtain estimates

419 of population abundance (e.g., by fitting to harvest and effort data) along with age compositions,

420 in which case there would be interaction between the two.

$421 \quad$ Posterior probability distributions were obtained for regional and lake-specific

422 parameters using MCMC simulation the same way as with the stock-recruitment relationships

423 above. Overall, we obtained posterior distributions for 260 parameters, including $3 \times 26$ stock-

424 recruitment parameters $\left(\alpha, \beta\right.$ and $\left.\sigma_{\mathrm{R}}\right)$ and $7 \times 26$ growth and maturation/selectivity parameters

$425\left(L_{\infty}, K, t_{0}, \sigma_{\mathrm{L}}, h, m\right.$, and $\left.M\right)$, a sub-sample of which was used as input to the forecasting model.

\section{Forecasting model}

428 To evaluate performances of walleye fisheries in northern Wisconsin regionally and in

429 individual lakes under alternative harvest policies (exploitation rates and allocations of tribal and

430 recreational harvest), we constructed an age-structured dynamic simulation model forecasting

431 total (ages 1-18 years) and adult abundances of walleye and tribal and recreational harvest over a

432 100-year time horizon. We parameterized the walleye simulation model using regional and lake-

433 specific posterior distributions of parameter estimates from the hierarchical Bayesian models

434 described above. Thus, the simulation model forecasted walleye abundance-at-age for regionally

435 and on a lake-by-lake basis. Regional and lake-specific recruitment to the first age class was 
436 generated using stock-recruitment relationships, which included stochasticity to allow for

437 interannual recruitment variation.

$438 \quad(26)$

$$
N_{i, 0, t}=\alpha_{i} S_{i, t} e^{-\beta_{i} S_{i, t}+e_{i, t}}
$$

439 Since the deviations $e_{i, t}$ in our estimation model combined measurement and process errors in

440 recruitment, the actual standard of inter-annual variability in recruitment for would less than our

441 estimates of $\sigma_{\mathrm{R}, i}$. Hansen et al. (2004) acknowledged that a large part of variability in Wisconsin

442 walleye recruitment was attributable to measurement error in the electrofishing estimates of

443 walleye recruitment. Additionally, previous studies indicated that the average standard deviation

444 of the logarithm of annual recruitment residuals over many fish species was around 0.6

445 (Beddington and Cooke 1983; Maunder and Deriso 2003). Therefore, we used one third of the

446 estimated $\sigma_{\mathrm{R}, i}$ as the standard deviation of inter-annual variability in forecasting future

447 recruitment, which is quite conservative given that measurement errors in electrofishing CPE

448 were estimated to be more than three times actual age-0 walleye variability (Hansen et al. 2004).

449 Numbers at age after recruitment were assumed to decrease exponentially over time and

450 were calculated using an accounting equation of the form:

451

$$
N_{i, a+1, t+1}=N_{i, a, t} e^{-M_{i, a}}\left(1-u_{\mathrm{s}, i} V_{i, a}^{\mathrm{spear}}-u_{\mathrm{r}, i} V_{i, a}^{\mathrm{rec}}\right)
$$

452 where $M$ estimates were based on Hansen et al. (2011) for younger age classes and our own

453 method for the five year and older age classes. Initial population density was set at abundance at 454 unfished equilibrium, calculated for each lake based on $R 0$ and natural morality, with adult

455 density being $R O \times$ SPR. Our estimates of adult density were within the range of equilibrium 456 adult density calculated by Schueller et al. (2012), in which the median adult density at unfished 457 equilibrium was $23.3 \mathrm{fish} \cdot \mathrm{ha}^{-1}$ (with a range of 14-55 fish $\cdot \mathrm{ha}^{-1}$ ). 
We evaluated changes in walleye abundance under various combinations of tribal and

459 recreational exploitation rates, assuming a logistic selectivity curve for spearing and a knife-age

460 selectivity function for angling (with a minimum length limit of $38 \mathrm{~cm}$ ), just as with the

461 estimation model. Given that the selectivity schedule for the spear fishery was assumed to be the

462 same as the walleye maturity schedule, the simulated age/size composition of spearing harvest

463 would be the same as that for the adult population. In addition, we evaluated changes in walleye

464 abundance under an alternative vulnerability schedule for the recreational fishery assuming that

465 all adults were fully vulnerable to angling, just as with the tribal fisheries.

466 Given a knife-age selectivity function for angling, some adult fish would not be

467 vulnerable to fishing in the recreational fishery depending on the minimum length limit, meaning

468 that the amount of fish harvested under a given exploitation rate would be less in the recreational

469 fishery than in the spearing fishery. To ensure the same number of fish would be harvested in

470 both fisheries despite a minimum length limit for angling, we adjusted the exploitation rate $\left(u_{\text {adj }}\right)$

471 for vulnerable age classes in the recreational fishery such that:

$$
u_{\text {adj }}=\tilde{u}_{r} * \frac{a d u l t}{v u l}
$$

473 where adult is the abundance of the adult population and $v u l$ is the total abundance of vulnerable 474 age classes given the minimum length limit.

475 We accounted for uncertainties in walleye population dynamics when evaluating 476 performances of alternative harvest policies by repeating the 100-year simulations under 1,000

477 combinations of: (1) stock-recruitment relationships; (2) VB growth functions; (3) natural 478 mortalities; and (4) maturity/vulnerability schedules. For each of the 1,000 simulations, the 479 forecasting model read in a different set of input values from the posterior distributions of 480 parameter estimates obtained using the MCMC simulations described above. We then compared 
481 performances of harvest policies using: (1) the median and interquartile range (IQR) of the

482 proportion of adult abundance remaining after 100 years of fishing; (2) the median and

483 interquartile range of long-term sustainable angling and spearing harvests (calculated as the

484 average harvest in years 50-100 to makes sure the population is at stable equilibrium); and (3)

485 probability of collapse based on the 1,000 simulations. It should be noted that the Ricker stock-

486 recruitment model would not give a reliable prediction of collapse if juvenile mortality increased

487 at low spawner abundances through depensation or Allee effects (Myers et al. 1999; Walters and

488 Kitchell 2001). To account for potential depensatory population dynamics, we used $10 \%$ of the

489 adult or population abundance at unfished equilibrium (as predicted by our simulation models) as

490 a threshold below which the population was considered to have functionally collapsed (Worm et

491 al. 2009). At 10\% of unfished stock size, recruitment is presumed to be severely reduced, and the

492 population would no longer play a substantial ecological role (Worm et al. 2009).

493

494 Results

495 Model fits and sensitivity analysis

496 Based on DIC, which was about 1403.86 for the lake-by-lake analysis (Table 2), we

497 selected the LNN-InvG model (Table 3) as the best model among the alternative models

498 evaluated (Table 4) to characterize the variation in stock-recruitment relationships of walleye

499 populations among the Ceded Territory lakes. Except for the NN model, all the alternative model

500 structures considered for model selection and sensitivity analysis met the criteria used to evaluate

501 model convergence. i.e., the MCMC chains for the parameters estimated were judged to have

502 converged to the underlying joint posterior probability distribution and to contain enough

503 information to characterize uncertainty in parameter estimates; trace plots showed no 
504 "stickiness", effective sample sizes showed that saved MCMC samples contained sufficient 505 information to characterize posterior probability distributions of parameter estimates and, the means of the first $10 \%$ and last $50 \%$ of the saved MCMC samples were similar, with the absolute

507 values of Geweke's (1992) Z-score of the differences between means of the first $10 \%$ and last $50850 \%$ being $<2$ for all parameters (Table 4). Using the base model estimate, we found that 509 predicted values also matched observed stock-recruitment data (Fig. 3).

510 Stock-recruitment parameter estimates were not sensitive to our assumptions of prior 511 distributions as evidenced by the test of similarity of $R_{0}$ estimates obtained under alternative 512 prior assumptions, with the absolute value of the pairwise Geweke's (1992) Z-scores being $<2$ 513 for almost all lakes (Table 4). Regional median $R_{0}$ estimates were in the range 20-23 fish $\cdot \mathrm{ha}^{-1}$

514 under the different prior assumptions; lake-specific median $R_{0}$ estimates under the different prior 515 assumptions were also within a 1-6 units of each other (Table 4). For three lakes (Lac Vieux 516 Desert, Squaw and Siskiwit), SPR values provided negative $R_{0}$ estimates, most likely because the

517 Hansen et al. (2011) method (eq. 19) over-estimated natural mortality. Therefore, we used 518 regional SPR when calculating $R_{0}$ for these lakes; negative equilibrium recruitment means that 519 the population is headed to extinction (Walters and Martell 2004). For the other population dynamics parameters, DIC values showed that the model with 521 lognormal priors for all paramours except $t_{0}$ best described the VB and maturity functions for 522 walleye in the Ceded Territory lakes. Apparently because the data are less noisy (Fig 4), the VB 523 and maturity parameters were even less sensitive to prior distributional assumptions. By contrast, 524 the stock-recruitment model fits show large residual errors (as is typical of other fisheries), with 525 the lake-specific values of $\sigma$ ranging from 1.6 to 2.4 (Fig. 3; Table 3), although these values 526 represented both inter-annual variability in recruitment and measurement errors. For brevity, we 
527 only report results from our analysis of sensitivity of the stock-recruitment relationships to

528 alternative model structures.

$530 \quad$ Population dynamics

In addition to the DIC being higher (1403.86), estimates of stock-recruitment

532 relationships obtained by fitting the Ricker model independently for each lake varied

533 substantially among lakes, with the limited number of years of (apparently less informative) data

534 for several lakes providing parameter estimates with very high degrees of uncertainty (CV)

535 (Table 2) and unrealistically high $\alpha$ (e.g., $\alpha=10493.93$ for North Twin lake) or negative $\beta$ (e.g.,

$536 \beta=-0.17$ for Squirrel Lake and -0.11 for Bearskin Lake) (Table 2). With $\alpha$ ranging from 0.09 to

53710493.93 and negative $\beta$ for several lakes, it was not possible to provide reasonable regional

538 estimates unless we excluded the lakes with biologically unrealistic parameter estimates. In

539 contrast, the hierarchical Bayesian analysis resulted in reasonable estimates of $\alpha$ and $\beta$ for all

540 lakes, without over-shrinkage of parameter estimates, as ascertained by the insensitivity of our

541 estimates to prior distributional assumptions (Table 3 and 4).

542 Stock-recruitment parameters from the hierarchical model also suggested that walleye

543 productivity varied considerably among northern Wisconsin lakes, with regional (LNN-InvG)

544 median $R_{0}$ estimated to be about 20 fish $\cdot \mathrm{ha}^{-1}$ (Table 4 ) and the associated stock-recruitment

545 parameters being $\alpha=2.768(95 \%$ Bayesian credible limits, $\mathrm{CL}=1.366,4.761), \beta=0.049(\mathrm{CL}=$

$5460.002,0.103)$, and $\sigma=1.964(\mathrm{CL}=1.931,2.643)$ (Table 3; parameter estimates from alternative

547 models are in Table A1). Lake-specific $R_{0}$ values ranged from 3.441 fish $\cdot$ ha $^{-1}$ for Annabelle Lake

548 to 70.714 fish $\cdot \mathrm{ha}^{-1}$ for Escanaba Lake, with the corresponding stock-recruitment parameters

549 estimated to be $\alpha=2.077(\mathrm{CL}=0.508,4.541), \beta=0.057(\mathrm{CL}=-0.007,0.136)$, and $\sigma=1.781$ 
$550(\mathrm{CL}=1.261,2.364)$ for Annabelle Lake and $\alpha=6.046(\mathrm{CL}=1.800,11.860), \beta=0.029(\mathrm{CL}=$ $5510.003,0.052)$, and $\sigma=1.612(\mathrm{CL}=1.212,1.887)$ for Escanaba Lake. Stock-recruitment

552 parameters estimated for Escanaba Lake were similar under the hierarchical and lake-by-lake 553 analyses, which is likely given the large amounts of (and apparently more informative) data for 554 this lake.

555 VB growth parameters were estimated with lower degrees of uncertainty than stock 556 recruitment parameters (compare CLs in Table 3 and 5). Variability in VB growth parameters 557 among lakes was also less pronounced (Table 5), with regional VB growth parameters estimated 558 at $L_{\infty}=68.61 \mathrm{~cm}(95 \% \mathrm{CL}=64.31 \mathrm{~cm}, 73.41 \mathrm{~cm}), K=0.13 \mathrm{yr}^{-1}\left(95 \% \mathrm{CL}=0.11 \mathrm{yr}^{-1}, 0.15 \mathrm{yr}^{-1}\right)$, 559 and $t_{0}=-1.23(95 \% \mathrm{CL}=-1.43,-1.02)$. Lake Siskiwit was an extreme case, with the lowest $L_{\infty}$ $560(\mathrm{HPD}=47.63 \mathrm{~cm} ; 95 \% \mathrm{CL}=46.25 \mathrm{~cm}, 49.07 \mathrm{~cm})$ and the highest $K\left(\mathrm{HPD}=0.24 \mathrm{yr}^{-1} ; 95 \% \mathrm{CL}\right.$

$\left.561=0.22 \mathrm{yr}^{-1}, 0.27 \mathrm{yr}^{-1}\right)$. Similarly, parameters of the logistic maturity and selectivity curves were 562 estimated with relatively low error (Table 6), with a regional $m=3.36(95 \% \mathrm{CL}=3.13,3.63)$

563 and $h=4.80(95 \% \mathrm{CL}=3.45,6.22)$; however, the slope of the logistic function $(h)$ varied more

564 than the age at 50\% maturity $(\mathrm{m})$. Regional natural mortality was also estimated with relatively

565 low error (Table 6), with HPD $=0.24 \mathrm{yr}^{-1}\left(95 \% \mathrm{CL}=0.17 \mathrm{yr}^{-1}, 0.35 \mathrm{yr}^{-1}\right)$, although very high or 566 very low natural mortalities were estimated for some lakes.

\section{Comparing performances of alternative harvest scenarios}

Although walleye population responses to fishing were predicted to be highly variable

570 due to high uncertainty in stock-recruitment parameter estimates, underlying trends were

571 evident. While the magnitude of population responses to fishing would be higher or lower for

572 individual lakes depending on their productivity, simulations based on the regional population 
573 and fishery parameters showed that the performance of walleye fisheries would vary depending

574 on exploitation rates and selectivity schedules assumed for recreational and tribal fisheries.

575 Based on the regional parameter estimates, adult density, which is equivalent to standing stock

576 biomass (SSB), decreased continuously as the exploitation rate increased. The effect of

577 exploitation was slightly lower under the scenarios with a 38-cm minimum length limit for the

578 recreational fishery (Fig. 5a) compared to fishing scenarios with logistic selectivity for both the

579 recreational and tribal fisheries (Fig. 5b). Recreational and tribal harvest increased with increased

580 fishing within exploitation rates in the range of $0-20 \%$, and declined with exploitation rates

581 above $20 \%$ (Fig. 5c and d). Assuming equal exploitation rates for the two fisheries, peak

582 combined recreational and tribal harvest was about $1.7 \mathrm{fish} \cdot \mathrm{ha}^{-1}$ on average under either of the

583 two combinations of selectivity schedules assumed for the two fisheries (Fig. 5c and d).

584 Similarly, the probability of collapse increased as the exploitation rate increased (Fig 5a and b),

585 and the risk of collapse was lower under the scenarios with a $38 \mathrm{~cm}$ minimum length limit than

586 logistic selectivity for the recreational fishery. Using SSB, total recreational and tribal harvest,

587 and probability of population collapse as performance metrics, simulations suggested that

588 northern Wisconsin walleye populations could sustain an optimal exploitation rate of about 20\%

589 on average given the existing combination of recreational and tribal selectivity schedules (Fig.

590 5).

Contour plots based on adult abundance under different combinations of recreational

592 angling and tribal spearing exploitation rates in the range of $0-25 \%$ indicated that adult density

593 would decrease continuously with exploitation rate (Fig. 6a). In contrast, combined recreational

594 and tribal harvest increased with increased exploitation rates in the range of $1-15 \%$ (i.e., up to a

595 total exploitation rate of $20 \%$ ), but decreased when combined recreational and tribal exploitation 
596 rate increased above $20 \%$ (Fig. 6b). These results indicate that a total exploitation rate of about

$59720 \%$ would yield the greatest long-term optimal harvests, assuming a $38-\mathrm{cm}$ minimum length

598 limit for the recreational fishery.

599 Regional adult abundance and harvest projections under a total exploitation rate of $35 \%$

600 (with a 38-cm minimum length limit for the recreational fishery) indicated that the largest

601 changes in response to fishing would occur during the first ten years or so of the fisheries.

602 Abundance and harvest stabilized in subsequent years, at a median adult density of about 4.30

603 fish $\cdot \mathrm{ha}^{-1}$ and total recreational and tribal harvest of about $1.20 \mathrm{fish} \cdot \mathrm{ha}^{-1}$ (Fig. 7). Given the

604 population and fishery parameters estimated for each lake (Tables 3, 5 and 6), lake-specific

605 optimal fishing scenarios can be higher or lower than was predicted to be optimal regionally. The

606 most productive lakes, such as Escanaba $\left(R_{0}=70.714 \mathrm{fish} \cdot \mathrm{ha}^{-1}\right)$, Middle Eau Claire $\left(R_{0},=50.831\right.$

607 fish $\left.\cdot \mathrm{ha}^{-1}\right)$, Sherman $\left(R_{0}=51.004 \mathrm{fish} \cdot \mathrm{ha}^{-1}\right)$, and Grindstone $\left(R_{0}=39.135 \mathrm{fish} \cdot \mathrm{ha}^{-1}\right)$ lakes would

608 yield the highest optimal harvests, whereas low productivity lakes, such as Annabelle $\left(R_{0}=\right.$

$\left.6093.441 \mathrm{fish} \cdot \mathrm{ha}^{-1}\right)$, Squaw $\left(R_{0}=5.208 \mathrm{fish} \cdot \mathrm{ha}^{-1}\right)$, and Siskiwit $\left(R_{0}=6.318 \mathrm{fish} \cdot \mathrm{ha}^{-1}\right)$ lakes would

610 provide the lowest optimal harvests, which is evident from our results showing probabilities of

611 population collapse for individual lakes under various exploitation rates (Table 7).

\section{Discussion}

Hierarchical Bayesian meta-analysis has been used in a number of fisheries management

615 applications as a means of making efficient use of uninformative data in the estimation of

616 population dynamics parameters (Chen and Holtby 2002; Michielsens and McAllister 2004;

617 Forrest et al. 2010). We expanded upon previous approaches by applying a hierarchical Bayesian

618 meta-analysis with alternative prior distributional assumptions to identify an appropriate model 
619 to describe population and fishery dynamics of walleye in multiple lakes in the Ceded Territory

620 of northern Wisconsin. Although time-series demographic data were available for walleye in

621 numerous lakes in northern Wisconsin, data sets for many of the lakes were not informative

622 enough or did not provide sufficient contrast to accurately describe walleye population

623 dynamics, especially their recruitment dynamics, resulting in unrealistic estimates of stock-

624 recruitment relationships for several lakes. In contrast, by accounting for an assumed underlying

625 similarity (Myers et al. 2001; Gelman et al. 2004) between lakes (which is plausible given the

626 broad-scale biological, environmental, and anthropogenic factors affecting recruitment dynamics

627 in individual lakes (Beard et al. 2003a)), a hierarchical Bayesian model allowed us to obtain

628 biologically reasonable combinations of $\alpha$ and $\beta$ for stock-recruitment curves that still fit

629 observed data very well. As such, our results highlight that in contrast to models fit to individual

630 lakes separately, assuming they share no similarities, and models that pool all the data, assuming

631 all lakes are identical, hierarchical models combine "the best of both worlds" by modeling lakes'

632 similarities but also allowing estimation of individual parameters. Additionally, by considering

633 alternative prior distributions, we were at the same time able to ensure that parameter values

634 were primarily influenced by data; thus, our modeling framework accommodated possible

635 skewness and excess variability among parameters and has not caused over-shrinkage of

636 parameter estimates toward average values. This was also evident from our lake-specific

637 estimates of unfished equilibrium recruitment $\left(R_{0}\right)$ and adult abundance that reflected the

638 observed recruitment data for individual lakes. Further, by comparing parameter estimates for

639 individual lakes from the hierarchical analysis including and excluding Escanaba Lake, we

640 showed that that lake-specific parameter estimates were not strongly influenced by the relatively 
641 larger amount of data from Escanaba Lake (results not shown), suggesting lake-specific

642 parameters were not pulled toward the regional average values.

643 In view of the above, we believe that the hierarchical approach allowed us to obtain more

644 accurate posterior distributions of stock-recruitment parameters, natural mortalities, maturity and

645 selectivity schedules, and growth parameters for individual lakes and to characterize the

646 variability in population productivity among lakes. Given the estimated posterior distributions

647 for the entire set of population and fishery parameters, it was possible for us to build a whole-

648 population forecasting model that accounted for uncertainty in all input parameters, one that

649 allowed us to evaluate the sustainability of alternative recreational and tribal harvest policies

650 regionally and in individual lakes in the Ceded Territory of northern Wisconsin. Besides

651 providing improved parameter estimates for individual lakes, our hierarchical Bayesian analysis

652 provided regional posterior distributions of parameter estimates representing multiple walleye

653 populations that can be used as priors in future assessments of walleye or similar populations in

654 other lakes (i.e., posterior predictive distribution), especially when available data are

655 uninformative.

656 While our hierarchical meta-analysis of the population dynamics of walleye in northern

657 Wisconsin lakes showed that productivities (particularly, stock-recruitment relationships) and

658 associated optimal harvest rates varied among lakes, the estimated optimal exploitation rates

659 (with a median of 20\%) are within the range of those estimated for other walleye populations in

660 North America, i.e., a median of 21\% and a maximum of about 56\% (Baccante and Colby 2003).

661 Our estimates were also similar to those of Lester et al. (2014), which suggested that sustainable

662 exploitation rates for walleye should be about $0.75 \cdot M$. Given our regional estimate of $M=0.24$

663 across all age classes, Lester et al. (2014) would predict an optimal exploitation rate of $18 \%$ for 
664 northern Wisconsin walleye populations. A recent analysis of walleye production and

665 exploitation on Escanaba Lake also suggested that annual exploitation rates $>20 \%$ reduced

666 surplus production (Rypel et al. 2015). Further, our estimates of mean optimal exploitation rates

667 were similar to those suggested in previous studies of walleyes in Wisconsin, including Staggs et

668 al. (1990) and Hansen et al. (1991). On the other hand, Schueller et al. (2008) concluded that an

669 exploitation rate of $35 \%$ may be the most optimal for the walleye populations; however, their

670 prediction was based on probability of population collapse.

671 Our estimates of optimal exploitation rates are also in concordance with existing walleye

672 harvest policy in northern Wisconsin, which aims to ensure that total exploitation rate does not

673 exceed $35 \%$ of the adult population in more than 1 out of 40 occasions (Beard et al. 2003b).

674 However, walleye populations in these lakes are generally exploited at lower rates; adult walleye

675 exploitation calculated as the sum of angling and spearing exploitation rates averaged about

$67613 \%$, with only four out of 210 lakes (1.9\%) sampled during 1990-1998 having experienced total

677 exploitation rates that exceeded 35\% (Beard et al. 2003b). However, these exploitation rates are

678 lower than those found for walleye in other North American lakes (Baccante and Colby 2003),

679 although some of the differences among the exploitation rates in our study and others could be

680 the result of differences in how exploitation rates were calculated. For example, Serns and

681 Kempinger (1981) calculated exploitation rates assuming age-3 and older walleye were fully

682 vulnerable to fishing, while our study used exploitation rates as a proportion of adult walleye

683 only. Yet, even if most northern Wisconsin lakes are typically exploited below the predicted

684 optimal exploitation rate, managing the walleye populations in these lakes under the same

685 harvest policy may not necessarily result in optimal yields given the variability in walleye

686 productivity among these lakes. Thus, walleye management policies for northern Wisconsin 
687 lakes should account for the variability in productivity among lakes when formulating

688 mismanagement policies. Ignoring the variability among these populations may lead to high-risk 689 management strategies being adopted for the least productive lakes, such as Squaw and Siskiwit 690 lakes. Conversely, assuming the same optimal exploitation rate for all lakes may lead to under691 exploitation of the most productive lakes, such Escanaba, Sherman, Middle Eau Claire, and 692 Grindstone lakes. Our results suggest that the walleye fisheries would perform better under size-selective 694 harvest policies in which only the largest age classes are vulnerable to fishing (lower probability 695 of collapse; higher SSB) (Fig 4). This is not surprising because delaying the age at entry of fish 696 to the harvestable population reduces the risk of overexploitation by allowing fish to mature and 697 spawn prior to harvest (Frisk et al. 2002). Even though it would result in suboptimal harvests, the walleye population was predicted to sustain exploitation rates over $35 \%$ under a $38 \mathrm{~cm}$ minimum 699 length limit for the recreational fishery. This implies that under highly size-selective harvest 700 policies, it may not be necessary to control exploitation rates, and the fishery can be left to self701 regulate. Indeed, inland fisheries managers generally rely on passive regulations, such as bag and 702 length limits, to regulate fisheries (Beard et al. 2003b; Post et al. 2002). However, recent 703 evidence suggests that self-regulation may not always maintain exploitation rates at sustainable

704 levels and a precautionary approach should be used to manage recreational fisheries (Radomski 705 et al. 2001; Cox et al. 2002; Allen et al. 2013).

Our results indicated that current Ceded Territory management policies ( 1 in 40

707 maximum acceptable risk of exploitation rates exceeding 35\%) and size-selectivity in the 708 recreational fishery are likely sufficient to sustain walleye populations in many northern 709 Wisconsin lakes, but not in all of them, suggesting the need for lake-specific management 
710 policies. However, with hundreds of lakes in northern Wisconsin that differ in ecosystem

711 characteristics, responsive lake-specific walleye management in the Ceded Territory may be

712 infeasible. Instead, regionally conservative management policies could be implemented to avoid

713 overexploitation in certain populations (low walleye productivity systems) at the expense of

714 some populations being potentially underexploited (high walleye productivity systems). Under

715 the "adult exploitation $\leq 35 \%$ " management system, mean adult density and age-0 walleye

716 relative abundance declined significantly in the Ceded Territory during 1990-2011 (Hansen et al.

717 2015), and mean adult walleye densities are now below the desired goal of $\geq 7.4$ fish $\cdot \mathrm{ha}^{-1}$ for

718 naturally reproducing walleye populations in the Ceded Territory (U.S. Department of the

719 Interior 1991). These negative trends in adult densities and walleye recruitment further suggest

720 that a conservative regional approach is needed for Ceded Territory walleye management.

721 Considering our estimates of regional optimal exploitation rates and the variability in

722 productivity among lakes, a reduction in the Ceded Territory of Wisconsin total allowable catch

723 walleye exploitation rate from $\leq 35 \%$ to about $20 \%$ may ensure optimal sustainable yields for

724 most of the lakes in this tribally and recreationally important fishery. This is also reasonable

725 considering the estimates of Lester et al. (2014) and Rypel et al. (2015), and the experimental

726 fishing studies on Big Crooked and Sherman lakes (Schueller et al. 2005; Schmalz et al. 2011;

727 G.G. Sass unpublished data).

728 Although our results could be used to guide walleye management policies, future

729 research could expand on our analysis of variability in life-history characteristics among northern

730 Wisconsin lakes. Variability in life history characteristics among populations is of critical

731 interest to population ecologists aiming not only to understand the inherent within-species

732 variability, but also to explore potential environmental covariates explaining variability in life 
733 history characteristics (Myers et al. 2001; Helser and Lin 2004). Although they did not use a

734 hierarchical modeling approach, Beard et al. (2003a) analyzed data from 162 northern Wisconsin

735 lakes during 1990-1999 to develop a regional stock-recruitment model for walleye and

736 identified density-independent factors explaining variability in recruitment, including

737 temperature (as represented by calendar year) and yellow perch density. Their findings were

738 similar to those of other studies on walleye stock-recruitment relationships (e.g., Madenjian et

739 al. 1996; Hansen et al. 1998). Similarly, Sass and Kitchell (2005) found strong correlations

740 between walleye growth and surrogate measures of lake productivity. Therefore, a logical next

741 step to our study would be to explore potential relationships between our estimates of lake-

742 specific population parameters and environmental covariates identified by Beard et al. (2003a),

743 Sass and Kitchell (2005), and others. Identifying variance components associated with density-

744 independent effects on lake productivity may help explain variability in stock-recruitment and

745 other population parameters among lakes and can lead to improved parameter estimation with

746 relatively low error. Similarly, (Hanson et al., 2004), accounting for density-independent

747 covariates may help explain inter-annual variability in recruitment for individual lakes,

748 especially persistent change or "nonstationarity" in recruitment dynamics (Walters and Martell,

749 2004). In this regard, accounting for temporal autocorrelation may be expected to explain some

750 of the inter-annual variability in recruitment, but our post hoc analysis of serial-autocorrelation

751 of recruitment residuals showed that temporal autocorrelation (estimated to be about 0.05 on

752 average for individual lakes) did not account for a large amount of variability in annual

753 recruitment.

754 Though the parameter estimates for walleye populations in northern Wisconsin from our

755 hierarchical meta-analysis may be generally more realistic than estimates from independent 
756 analyses, alternative model assumptions (i.e., observation and/or process submodel hypotheses)

757 can be considered to minimize potential bias regarding some aspects of our assessment.

758 Particularly, while some population parameters are potentially correlated, we assumed that all

759 parameters were independent except for the Ricker $\alpha$ and $\beta$, and this may have led to some bias

760 in our estimates. For example, growth parameters $L_{\infty}$ and $K$ are generally known to be negatively

761 correlated among fishes (Helser and Lin 2004). Therefore, accounting for these correlations may

762 lead to somewhat better estimates. Further, our age-structured model did not track population

763 numbers over time, but pooled together age composition data over time. Although it would be

764 computationally more expensive, developing a full hierarchical Bayesian statistical catch-at-age

765 model that accounts for these and other potential correlations could lead to more accurate

766 representations of the dynamics of walleye populations in northern Wisconsin lakes. Finally,

767 aging bias may occur due to the use of scales and dorsal fin spines instead of otoliths, pointing to

768 the need to apply an aging error correction matrix. However, Koenigs et al. (2013) suggested that

769 there is minimal difference between otoliths and dorsal spines in aging older age classes. In

770 addition, any potential age estimation bias associated with the Wisconsin Ceded Territory's

771 walleye sampling protocols, which have been in place since 1990, would only be significant for

772 the older age classes (e.g., ages 10+), and thus would have negligible effects on our estimates of

773 natural mortality; based on our age composition data, these age classes comprise a very low

774 proportion of total walleye densities. Finally, while we selected the best model to represent

775 walleye dynamics in the Ceded Territory using DIC results and MCMC diagnostics, alternatively

776 we may use multi-model averaging using DIC weights to make inferences based on all candidate

777 models that fit the data well enough to appear plausible. However, because the difference in DIC

778 between the best model and alternative models is greater than 10, DIC weights would be close to 
7791 for the best selected model (Burnham and Anderson 2002). In addition, Wilberg and Bence

780 (2008) showed using simulations that DIC usually selected the structurally most appropriate

781 model and that estimates based on the selected model and on model averaging were almost

782 equally unbiased. Either way, given that our model estimates were not very sensitive to

783 assumptions on priors, we anticipate that inferences made based on model averaging would not

784 be very different from those based on the best selected model.

785

\section{Acknowledgements}

787 We thank the Great Lakes Indian Fish and Wildlife Commission (GLIFWC) (Neil Kmiecik, 788 Mark Luehring, Joe Dan Rose) and the Wisconsin Department of Natural Resources (WDNR)

789 (Ron Bruch, Tom Cichosz, Gretchen Hansen, Jon Hansen, Jennifer Hauxwell, Joe Hennessey,

790 Steve Hewett, Andrew Rypel, Mike Staggs) for providing data to develop the models and for

791 their advice during model development. We are particularly indebted to all of the past and

792 current employees of GLIFWC and WDNR who collected the field data used in this study. We

793 also thank Matt Catalano, Mike Hansen, John Hoenig, Dan Isermann, and Mike Prager for

794 providing technical advice or reviewing of this manuscript. Funding for this project was provided

795 by the U.S. Fish and Wildlife Service, Federal Aid in Sportfish Restoration Program through the

796 Bureau of Sciences Services and Fisheries Management, WDNR. We acknowledge additional

797 financial support from the Quantitative Fisheries Center at Michigan State University. This is

798 manuscript 20XX-XX of the Quantitative Fisheries Center at Michigan State University.

799

$800 \quad$ References 
ADMB Project. 2013. Random Effects in AD Model Builder: ADMB-RE User Guide. ADMB Foundation, Honolulu, Hawaii.

Allen, M.S., Ahrens, R.N.M., Hansen, M.J., and Arlinghaus, R. 2013. Dynamic angling effort influences the value of minimum-length limits to prevent recruitment overfishing. Fish. Manag. Ecol. 20(2-3): 247-257.

Baccante, D.A., and Colby. 2003. Harvest, density and reproductive characteristics of North American walleye populations. Ann. Zool. Fennici 33: 601-615.

Beard, T.D., Hansen, M.J., and Carpenter, S.R. 2003a. Development of a regional stockrecruitment model for understanding factors affecting walleye recruitment in northern Wisconsin lakes. Trans. Am. Fish. Soc. 132(2): 382-391.

Beard, T.D., Rasmussen, P.W., Cox, S., and Carpenter, S.R. 2003b. Evaluation of a management system for a mixed walleye spearing and angling fishery in northern Wisconsin. N. Am. J. Fish. Manage. 23(2): 481-491.

Beddington, J.R., and Cooke, J.G. 1983. The Potential yield of fish stocks. FAO Fish. Tech. Pap., Rome, Italy.

Burnham, K.P., and Anderson, D.R. 2002. Model Selection and Multimodel Inference: A Practical Information-theoretic Approach. 2nd ed. Springer, New York.

Chen, D.G., and Holtby, L.B. 2002. A regional meta-model for stock-recruitment analysis using an empirical Bayesian approach. Can. J. Fish. Aquat. Sci. 59(9): 1503-1514.

Cichosz, T.A. 2012. Wisconsin Department of Natural Resources 2010-2011 Ceded Territory Fishery Assessment Report. Annual report, Department of Natural Resources, Bureau of Fisheries Management, Madison, Wisconsin. 
823 Conn, P.B., Williams, E.H., and Shertzer, K.W. 2010. When can we reliably estimate the 824 productivity of fish stocks? Can. J. Fish. Aquat. Sci. 67(3): 511-523.

825 Cox, S.P., Beard, T.D., and Walters, C. 2002. Harvest control in open-access sport fisheries: hot 826 rod or asleep at the reel? Bull. Mar. Sci. 70(2): 749-761.

827 Deriso, R.B., Quinn II, T.J., and Neal, P.R. 1985. Catch-Age Analysis with Auxiliary

828 Information. Can. J. Fish. Aquat. Sci. 42(4): 815-824.

829 Evans, M., Hastings, N., and Peacock, B. 2000. Statistical Distributions, 3rd edition. Wiley and $830 \quad$ Sons, New York.

831 Forrest, R.E., McAllister, M.K., Dorn, M.W., Martell, S.J.D., and Stanley, R.D. 2010. Hierarchical Bayesian estimation of recruitment parameters and reference points for Pacific rockfishes (Sebastes spp.) under alternative assumptions about the stock-recruit function. Can. J. Fish. Aquat. Sci. 67(10): 1611-1634.

Fournier, D.A., Skaug, H.J., Ancheta, J., Ianelli, J., Magnusson, A., Maunder, M., Nielsen, A., and Sibert, J. 2012. AD Model Builder: using automatic differentiation for statistical inference of highly parameterized complex nonlinear models. Optim. Meth. Softw. 27: $233-249$.

Frisk, M.G., Miller, T.J., and Fogarty, M.J. 2002. The population dynamics of little skate Leucoraja erinacea, winter skate Leucoraja ocellata, and barndoor skate Dipturus laevis: predicting exploitation limits using matrix analyses. ICES J. Mar. Sci. 59(3): 576-586.

Gelman, A., Carlin, J.B., Stern, H.S., and Rubin, D.B. 2004. Bayesian Data Analysis. In 2nd edition. Chapman and Hall/CRC. 
844 Geweke, J. 1992. Evaluating the accuracy of sampling-based approaches to the calculation of 845 posterior moments. In Bayesian Statistics. Edited by J.M. Bernardo, J.O. Berger, A.P.

847 Gibson, F., and Myers, R.A. 2003. A meta-analysis of the habitat carrying capacity and maximum reproductive rate of anadromous alewife in eastern North America. In Status and conservation of shads worldwide; Biodiversity, status, and conservation of the

Hansen, G.J.A., Carpenter, S.R., Gaeta, J.W., Hennessy, J.M., Vander Zanden, M.J., and Tierney, K. 2015. Predicting walleye recruitment as a tool for prioritizing management actions. Can. J. Fish. Aquat. Sci. 72(5): 661-672.

854 Hansen, J.F., Sass, G.G., Gaeta, J.W., Hansen, G.A., Isermann, D.A., Lyons, J., and Vander Zanden, M.J. 2015. Largemouth bass management in Wisconsin: intra- and inter-specific implications of abundance increases. In Proceedings of the Black Bass Diversity: Multidisciplinary Science for Conservation Symposium. American Fisheries Society, Bethesda, MD. pp. 31-50.

Hansen, M.J., Beard, T.D., and Hewett, S.W. 2000. Catch rates and catchability of walleyes in

862 Hansen, M.J., Bozek, M.A., Newby, J.R., Newman, S.P., and Staggs, M.D. 1998. Factors angling and spearing fisheries in northern Wisconsin lakes. N. Am. J. Fish. Manage. affecting recruitment of walleyes in Escanaba Lake, Wisconsin, 1958-1996. N. Am. J. Fish. Manage. 18(4): 764-774. 
865 Hansen, M.J., Fayram, A.H., and Newman, S.P. 2011. Natural mortality in relation to age and 866 fishing mortality on walleyes in Escanaba Lake, Wisconsin, during 1956-2009. N. Am. J. Fish. Manage. 31(3): 506-514.

868

869

870

871

872

873

874

875

876

877

878

879

880

Hansen, M.J., Newman, S.P., and Edwards, C.J. 2004. A reexamination of the relationship between electrofishing catch rate and age-0 walleye density in northern Wisconsin lakes. N. Am. J. Fish. Manage. 24(2): 429-439.

Hansen, M.J., Staggs, M.D., and Hoff, M.H. 1991. Derivation of safety factors for setting harvest quotas on adult walleyes from past estimates of abundance. Trans. Am. Fish. Soc. 120(5): $620-628$.

He, J.X., and Bence, J.R. 2007. Modeling Annual Growth Variation using a Hierarchical Bayesian Approach and the von Bertalanffy Growth Function, with Application to Lake Trout in Southern Lake Huron. Transactions of the American Fisheries Society 136(2): $318-330$.

He, J.X., Bence, J.R., Johnson, J.E., Clapp, D.F., and Ebener, M.P. 2008. Modeling variation in mass-length relations and condition indices of lake trout and Chinook salmon in Lake Huron: A hierarchical Bayesian approach. Trans. Am. Fish. Soc. 137(3): 801-817.

Helser, T.E., and Lin, H. 2004. A Bayesian hierarchical meta-analysis of fish growth: with an example for North American largemouth bass, Micropterus salmoides. Ecol. Model. 178: $399-416$.

Koenigs, R.P., Bruch, R.M., and Kamke, K.K. 2013. Impacts of Aging Error on Walleye Management in the Winnebago System. North American Journal of Fisheries Management 33(5): 900-908. 
887 Lee, H.-H., Maunder, M.N., Piner, K.R., and Methot, R.D. 2012. Can steepness of the stock-

888 recruitment relationship be estimated in fishery stock assessment models? Fish. Res.

889 125-126: 254-261.

890 Lester, N.P., Shuter, B.J., Venturelli, P., and Nadeau, D. 2014. Life-history plasticity and

891 sustainable exploitation: a theory of growth compensation applied to walleye

892 management. Ecol. Appl. 24(1): 38-54.

893 Madenjian, C.P., Tyson, J.T., Knight, R.L., Kershner, M.W., and Hansen, M.J. 1996. First-year

894 growth, recruitment, and maturity of walleyes in western Lake Erie. Trans. Am. Fish.

$895 \quad$ Soc. 125(6): 821-830.

896 Magnusson, A., and Hilborn, R. 2007. What makes fisheries data informative? Fish. Fish. 8(4):

$897 \quad 337-358$.

898 Maunder, M.N. 2003. Paradigm Shifts in Fisheries Stock Assessment: From Integrated Analysis

899 to Bayesian Analysis and Back Again. Nat. Resour. Model. 16(4): 465-475.

900 Maunder, M.N., and Deriso, R.B. 2003. Estimation of recruitment in catch-at-age models. Can. J.

$901 \quad$ Fish. Aquat. Sci. 60(10): 1204-1216.

902 Maunder, M.N., and Piner, K.R. 2015. Contemporary fisheries stock assessment: many issues

903 still remain. ICES J. Mar. Sci. 72(1): 7-18.

904 Meyer, R., and Millar, R.B. 1999. BUGS in Bayesian stock assessments. Can. J. Fish. Aquat.

905 Sci. 56(6): 1078-1087.

906 Michielsens, C.G., and McAllister, M.K. 2004. A Bayesian hierarchical analysis of stock-recruit

907 data: quantifying structural and parameter uncertainties. Can. J. Fish. Aquat. Sci. 61(6):

$908 \quad 1032-1047$. 
909 Millar, R.B., and Methot, R.D. 2002. Age-structured meta-analysis of U.S. West Coast rockfish 910 (Scorpaenidae) populations and hierarchical modeling of trawl survey catchabilities. Can. 911 J. Fish. Aquat. Sci. 59(2): 383-392.

912 Myers, R.A., Bowen, K.G., and Barrowman, N.J. 1999. Maximum reproductive rate of fish at 913 low population sizes. Can. J. Fish. Aquat. Sci. 56(12): 2404-2419.

914 Myers, R.A., MacKenzie, B.R., Bowen, K.G., and Barrowman, N.J. 2001. What is the carrying 915 capacity for fish in the ocean? A meta-analysis of population dynamics of North Atlantic 916 cod. Can. J. Fish. Aquat. Sci. 58: 1464-1476.

917 Myers, R.A., Smith, M.W., Hoenig, J.M., Kmiecik, N., Luehring, M.A., Drake, M.T., Schmalz, 918 P.J., and Sass, G.G. 2014. Size- and sex-specific capture and harvest selectivity of 919 walleyes from tagging studies. Trans. Am. Fish. Soc. 143(2): 438-450.

920 Nate, N.A., Bozek, M.A., Hansen, M.J., and Hewett, S.W. 2000. Variation in walleye abundance 921 with lake size and recruitment source. N. Am. J. Fish. Manage. 20(1): 119-126.

922 Nate, N.A., Bozek, M.A., Hansen, M.J., and Hewett, S.W. 2001. Variation of adult walleye 923 abundance in relation to recruitment and limnological variables in northern Wisconsin 924 lakes. N. Am. J. Fish. Manage. 21(3): 441-447.

925 Pilling, G.M., Kirkwood, G.P., and Walker, S.G. 2002. An improved method for estimating 926 individual growth variability in fish, and the correlation between von Bertalanffy growth 927 parameters. Can. J. Fish. Aquat. Sci. 59(3): 424-432.

928 Plummer, M., Best, N., Cowles, K., and Vines, K. 2010. Output analysis and diagnostics for 929 MCMC, R package version 0.14-2. Available: CRAN.Rproject.org/package = coda. 
930 Post, J.R., Sullivan, M., Cox, S., Lester, N.P., Walters, C.J., Parkinson, E.A., Paul, A.J., Jackson, 931 L., and Shuter, B.J. 2002. Canada's recreational fisheries: the invisible collapse?

$932 \quad$ Fisheries 27(1): 6-17.

933 Radomski, P.J., Grant, G.C., Jacobson, P.C., and Cook, M.F. 2001. Visions for recreational 934 fishing regulations. Fisheries 26(5): 7-18.

935 Rypel, A.L., Goto, D., Sass, G.G., and Vander Zanden, M.J. 2015. Production rates of walleye 936 and their relationship to exploitation in Escanaba Lake, Wisconsin, 1965-2009. Can. J. 937 Fish. Aquat. Sci. 72(6): 834-844.

938 Sass, G.G., and Kitchell, J.F. 2005. Can growth be used as a surrogate measure of walleye 939 (Sander vitreus) abundance change? Can. J. Fish. Aquat. Sci. 62(9): 2159-2168.

940 Schmalz, P.I., Fayram, A.H., Isermann, D.A., Newman, S.P., and Edwards, C.J. 2011. Harvest 941 and exploitation. In Biology, Management, and Culture of Walleye and Saugeulture.

943 Schueller, A.M., Fayram, A.H., and Hansen, M.J. 2012. Simulated equilibrium walleye population density under static and dynamic recreational angling effort. N. Am. J. Fish.

Schueller, A.M., Hansen, M.J., and Newman, S.P. 2008. Modeling the sustainability of walleye populations in northern Wisconsin lakes. N. Am. J. Fish. Manage. 28(6): 1916-1927.

948 Schueller, A.M., Hansen, M.J., Newman, S.P., and Edwards, C.J. 2005. Density dependence of walleye maturity and fecundity in Big Crooked Lake, Wisconsin, 1997-2003. N. Am. J. Fish. Manage. 25(3): 841-847.

Serns, S.L., and Kempinger, J.J. 1981. Relationship of angler exploitation to the size, age, and sex of walleyes in Escanaba Lake, Wisconsin. Trans. Am. Fish. Soc. 110(2): 216-220. 
953 Spiegelhalter, D.J., Best, N.G., Carlin, B.P., and Van Der Linde, A. 2002. Bayesian measures of 954 model complexity and fit. J. R. Stat. Soc. Ser. B 64(4): 583-639.

955 Staggs, M.D., Moody, M.H., Hansen, M.J., and Hoff, M.H. 1990. Spearing and sport angling for 956 walleye in Wisconsin's ceded territory. Administrative Report, Department of Natural 957 Resources, Bureau of Fisheries Management, Madison, Wisconsin.

958 Su, Z., and Peterman, R.M. 2012. Performance of a Bayesian state-space model of semelparous 959 species for stock-recruitment data subject to measurement error. Ecological Modelling 224(1): 76-89.

961 Tsehaye, I., Catalano, M., Sass, G., Glover, D., and Roth, B. 2013. Prospects for Fishery-Induced 962 Collapse of Invasive Asian Carp in the Illinois River. Fisheries 38(10): 445-454.

U.S. Department of the Interior. 1991. Casting light upon the waters: a joint fishery assessment of the Wisconsin Ceded Territory. Bureau of Indian Affairs, Minniapolis, Minnesota.

Walters, C.J., and Martell, S.J.D. 2004. Fisheries Ecology and Management. Princeton University Press, Princeton, New Jersey.

Walters, C., and Kitchell, J.F. 2001. Cultivation/depensation effects on juvenile survival and recruitment: implications for the theory of fishing. Can. J. Fish. Aquat. Sci. 58(1): 39-50. in statistical catch-at-age analysis. Fish. Res. 93, 212-221.

Worm, B., Hilborn, R., Baum, J.K., Branch, T.A., Collie, J.S., Costello, C., Fogarty, M.J., Fulton, E.A., Hutchings, J.A., Jennings, S., Jensen, O.P., Lotze, H.K., Mace, P.M., McClanahan, T.R., Minto, C., Palumbi, S.R., Parma, A.M., Ricard, D., Rosenberg, A.A., Watson, R., and Zeller, D. 2009. Rebuilding global fisheries. Science 325(5940): 578- 
977 Table 1. List of parameters and variables used in the hierarchical Bayesian meta-analysis of

978 northern Wisconsin walleye (Sander vitreus) population dynamics.

\begin{tabular}{ll}
\hline Symbol & Description \\
\hline Index variables & Lake \\
$i$ & Year \\
$t$ & Individual fish \\
$j$ & Age
\end{tabular}

Parameters and derived quantities

\begin{tabular}{|c|c|}
\hline$N$ & Abundance at the beginning of the year \\
\hline$R$ & Predicted number of recruits \\
\hline$\hat{R}$ & Observed number of recruits \\
\hline$S$ & Predicted spawning stock \\
\hline$\hat{S}$ & Observed spawning stock \\
\hline$\alpha$ & Recruits per spawner at low stock size \\
\hline$\beta$ & Degree of compensation \\
\hline$\omega$ & Deviations in annual recruitment \\
\hline$\sigma_{\mathrm{R}}$ & Standard deviation of inter-annual recruitment variability \\
\hline$v$ & Spawning stock measurement error \\
\hline$\sigma_{\mathrm{S}}$ & Standard deviation of measurement error for spawning stock \\
\hline $\bar{\alpha}$ & Median $\alpha$ \\
\hline $\bar{\beta}$ & Mean $\beta$ \\
\hline$\varepsilon_{\alpha}$ & Process error for $\alpha$ \\
\hline$\varepsilon_{\beta}$ & Process error for $\beta$ \\
\hline$\sum$ & Variance-covariance matrix between $\varepsilon_{\alpha}$ and $\varepsilon_{\beta}$ \\
\hline$\varepsilon_{\sigma_{\mathrm{R}}}$ & Process error for $\sigma_{\mathrm{R}}$ \\
\hline$\sigma_{\sigma_{\mathrm{R}}}$ & Standard deviation of $\varepsilon_{\sigma_{R}}$ \\
\hline$L$ & Length of fish \\
\hline$K$ & Growth coefficient \\
\hline$t_{0}$ & Time at zero length \\
\hline$L_{\infty}$ & Asymptotic length \\
\hline$\xi$ & Individual variation in length-at-age \\
\hline$\sigma_{\mathrm{L}}$ & Standard deviation of $\xi$ \\
\hline$\overline{L_{\infty}}$ & Median $L_{\infty}$ \\
\hline $\bar{K}$ & Median $K$ \\
\hline$\overline{t_{0}}$ & Mean $t_{0}$ \\
\hline$\varepsilon_{\mathrm{L}_{\infty}}$ & Process error for $L_{\infty}$ \\
\hline$\varepsilon_{\mathrm{K}}$ & Process error for $K$ \\
\hline
\end{tabular}




\begin{tabular}{|c|c|}
\hline$\varepsilon_{\mathrm{t}_{0}}$ & Process error for $t_{0}$ \\
\hline$\sigma_{\mathrm{L}_{\infty}}$ & Standard deviation of $\varepsilon_{\mathrm{L}_{\infty}}$ \\
\hline$\sigma_{\mathrm{K}}$ & Standard deviation of $\varepsilon_{\mathrm{K}}$ \\
\hline$\sigma_{\mathrm{t}_{0}}$ & Standard deviation of $\varepsilon_{\mathrm{t}_{0}}$ \\
\hline$V^{\text {spear }}$ & Tribal spearing selectivity/maturation probability \\
\hline$V^{\mathrm{rec}}$ & Recreational angling selectivity \\
\hline$h$ & Slope of the logistic selectivity/maturation function \\
\hline$m$ & Age at $50 \%$ maturity/vulnerability \\
\hline $\bar{h}$ & Median $h$ \\
\hline $\bar{m}$ & Median $m$ \\
\hline$\varepsilon_{\mathrm{h}}$ & Process error for $h$ \\
\hline$\varepsilon_{\mathrm{m}}$ & Process error for $m$ \\
\hline$\sigma_{\mathrm{h}}$ & Standard deviation of $\varepsilon_{\mathrm{h}}$ \\
\hline$\sigma_{\mathrm{m}}$ & Standard deviation of $\varepsilon_{\mathrm{m}}$ \\
\hline$V^{\mathrm{rec}}$ & Angling selectivity \\
\hline$F$ & Instantaneous fishing mortality \\
\hline$u_{\mathrm{s}}$ & Spearing exploitation rate \\
\hline$u_{\mathrm{r}}$ & Angling exploitation rate \\
\hline$M$ & Instantaneous natural mortality $\left(\mathrm{yr}^{-1}\right)$ \\
\hline $\bar{M}$ & Median natural mortality \\
\hline$Z$ & Total instantaneous mortality rate $\left(\mathrm{yr}^{-1}\right)$ \\
\hline$\varepsilon_{\mathrm{M}}$ & Process error for $M$ \\
\hline$\sigma_{\mathrm{M}}$ & Standard deviation of $\varepsilon_{\mathrm{M}}$ \\
\hline$N^{\text {mat }}$ & Number of mature fish at age \\
\hline $\operatorname{tot} N^{\mathrm{mat}}$ & Total number of mature fish \\
\hline$P$ & Predicted proportion of mature fish at age \\
\hline$\hat{P}$ & Observed proportion of mature fish at age \\
\hline$n$ & Effective sample size \\
\hline$\alpha{ }^{\prime}$ & Shape parameter for inverse-gamma distribution \\
\hline$\beta^{\prime}$ & Scale parameter for inverse-gamma distribution \\
\hline$R_{0}$ & Recruitment at unfished equilibrium \\
\hline SPR & Spawners per recruit in the absence of fishing \\
\hline $\mathrm{DIC}$ & Deviance information criterion \\
\hline $\bar{D}$ & Average deviance, measuring model fit \\
\hline$p_{D}$ & Effective number of parameters \\
\hline$C$ & Number of MCMC samples saved minus burn-in \\
\hline$\theta$ & All estimated parameters \\
\hline$D(\bar{\theta})$ & Deviance evaluated at the HPD parameter estimates \\
\hline
\end{tabular}


980 Table 2. Ricker stock-recruitment parameters (and associated \% asymptotic coefficients of

981 variation) for northern Wisconsin walleye (Sander vitreus) estimated for individual lakes

982 independently; the regional values were calculated by excluding lakes with unreasonably large $\alpha$

983 and negative $\beta$. Number of years of data used in estimating stock-recruitment parameters are

984 shown for each lake.

\begin{tabular}{|c|c|c|c|c|}
\hline Lake & Years of data & $\alpha$ & $\beta$ & $\sigma$ \\
\hline Regional & - & 9.88 & 0.29 & 2.15 \\
\hline Butternut (Forest)* & 23 & $19.46(133.72)$ & $0.29(52.38)$ & $3.04(14.74)$ \\
\hline Franklin & 6 & $5.91(125.30)$ & $0.35(56.13)$ & $1.98(28.87)$ \\
\hline Bearskin & 10 & $0.09(183.01)$ & $-0.11(67.78)$ & $2.17(22.36)$ \\
\hline Squirrel & 24 & $0.19(149.54)$ & $-0.17(68.63)$ & $1.66(14.43)$ \\
\hline Big Arbor Vitae & 7 & $9.86(243.68)$ & $0.13(113.08)$ & $1.56(26.73)$ \\
\hline Pelican & 8 & $6.09(261.92)$ & $0.38(86.20)$ & $3.52(25.00)$ \\
\hline Big St Germain & 6 & $16.12(545.42)$ & $0.36(182.03)$ & $4.58(28.87)$ \\
\hline Plum & 7 & $21.32(0.57)$ & $0.18(18.33)$ & $1.3(26.73)$ \\
\hline Star & 7 & $312.46(0.07)$ & $0.44(30.02)$ & $1.64(26.73)$ \\
\hline North Twin & 6 & $10493.93(0.06)$ & $1.29(44.67)$ & $1.9(28.87)$ \\
\hline Lac Vieux Desert & 7 & $14.12(685.67)$ & $0.65(185.94)$ & $2.9(26.73)$ \\
\hline Sherman & 18 & $18.09(98.91)$ & $0.12(80.08)$ & $1.99(16.67)$ \\
\hline Squaw & 22 & $0.5(127.07)$ & $-0.04(340.54)$ & $1.68(15.08)$ \\
\hline Butternut (Price)* & 6 & $5.31(218.68)$ & $0.14(144.40)$ & $1.97(28.87)$ \\
\hline Wolf & 16 & $1.82(263.00)$ & $0.04(374.31)$ & $3.17(17.68)$ \\
\hline Big Crooked & 21 & $0.86(134.92)$ & $0(9349.02)$ & $3.98(15.43)$ \\
\hline Escanaba & 46 & $6.64(41.55)$ & $0.03(41.29)$ & $1.4(10.43)$ \\
\hline Grindstone & 6 & $137.95(0.03)$ & $0.6(38.98)$ & $1.16(28.87)$ \\
\hline Round & 6 & $3.84(129.63)$ & $0.05(488.74)$ & $1.44(28.87)$ \\
\hline Bass Patterson & 18 & $15.94(82.09)$ & $0.14(38.66)$ & $1.67(16.67)$ \\
\hline Lower Eau Claire & 6 & $0.28(283.71)$ & $-0.21(179.54)$ & $2.63(28.87)$ \\
\hline Middle Eau Claire & 7 & $3.05(117.04)$ & $-0.08(127.43)$ & $0.83(26.73)$ \\
\hline Siskiwit & 17 & $1.57(65.71)$ & $0.08(77.42)$ & $1.78(17.15)$ \\
\hline Pine & 7 & $18.09(279.25)$ & $0.23(77.05)$ & $2.35(26.73)$ \\
\hline Annabelle & 9 & $2.84(108.83)$ & $0.14(95.05)$ & $1.46(23.57)$ \\
\hline
\end{tabular}


986 Table 3. Highest posterior density (HPD) estimates and lower and upper 95\% Bayesian credible 987 limits of regional and lake-specific Ricker stock-recruitment parameters for northern Wisconsin 988 walleye (Sander vitreus) populations estimated using the base (LNN-InvG) model.

\begin{tabular}{|c|c|c|c|}
\hline Lake & $\alpha$ & $\beta$ & $\sigma$ \\
\hline Regional & $2.768(1.366,4.761)$ & $0.049(0.002,0.103)$ & $1.964(1.931,2.643)$ \\
\hline Butternut (Forest) & $2.731(0.775,5.495)$ & $0.049(-0.005,0.120)$ & $2.401(2.208,3.534)$ \\
\hline Franklin & $2.059(0.413,5.064)$ & $0.057(-0.004,0.139)$ & $1.881(1.452,3.015)$ \\
\hline Bearskin & $3.312(0.702,6.406)$ & $0.045(0.000,0.075)$ & $1.973(1.591,2.962)$ \\
\hline Squirrel & $2.988(1.082,5.284)$ & $0.047(0.000,0.090)$ & $1.813(1.398,2.352)$ \\
\hline Big Arbor Vitae & $2.719(0.687,5.524)$ & $0.050(0.000,0.102)$ & $1.787(1.278,2.456)$ \\
\hline Pelican & $1.643(0.312,4.619)$ & $0.062(-0.005,0.146)$ & $2.203(1.989,3.671)$ \\
\hline Big St Germain & $2.292(0.363,5.708)$ & $0.054(-0.006,0.123)$ & $2.254(2.164,3.783)$ \\
\hline Plum & $3.733(0.949,8.084)$ & $0.041(-0.006,0.088)$ & $1.759(1.154,2.517)$ \\
\hline Star & $3.548(0.896,7.456)$ & $0.043(-0.005,0.097)$ & $1.861(1.357,2.976)$ \\
\hline North Twin & $3.261(0.668,7.447)$ & $0.045(-0.009,0.113)$ & $2.101(1.862,3.646)$ \\
\hline Lac Vieux Desert & $1.777(0.362,4.901)$ & $0.060(-0.004,0.144)$ & $2.362(2.301,3.828)$ \\
\hline Sherman & $5.231(1.637,10.080)$ & $0.033(-0.006,0.072)$ & $1.844(1.423,2.541)$ \\
\hline Squaw & $1.674(0.542,3.980)$ & $0.062(-0.001,0.150)$ & $1.757(1.346,2.235)$ \\
\hline Butternut (Price) & $2.514(0.463,5.260)$ & $0.052(-0.005,0.115)$ & $1.838(1.348,3.213)$ \\
\hline Wolf & $2.285(0.679,4.923)$ & $0.054(-0.001,0.127)$ & $2.263(2.043,3.602)$ \\
\hline Big Crooked & $2.003(0.579,4.725)$ & $0.057(0.000,0.123)$ & $2.304(2.096,3.413)$ \\
\hline Escanaba & $6.046(1.800,11.860)$ & $0.029(0.003,0.052)$ & $1.612(1.212,1.887)$ \\
\hline Grindstone & $4.192(0.937,10.360)$ & $0.039(-0.004,0.098)$ & $1.854(1.365,2.901)$ \\
\hline Round & $3.111(0.786,6.687)$ & $0.046(-0.004,0.107)$ & $1.791(1.140,2.477)$ \\
\hline Bass Patterson & $3.484(1.143,6.504)$ & $0.043(0.000,0.084)$ & $1.818(1.458,2.446)$ \\
\hline Lower Eau Claire & $2.461(0.517,5.359)$ & $0.052(-0.006,0.124)$ & $1.921(1.487,3.111)$ \\
\hline Middle Eau Claire & $5.014(1.146,11.500)$ & $0.034(-0.020,0.071)$ & $1.772(1.159,2.553)$ \\
\hline Siskiwit & $1.749(0.528,4.116)$ & $0.061(0.000,0.141)$ & $1.728(1.223,2.363)$ \\
\hline Pine & $2.018(0.404,4.756)$ & $0.057(0.000,0.131)$ & $1.924(1.489,2.960)$ \\
\hline Annabelle & $2.077(0.508,4.541)$ & $0.057(-0.007,0.136)$ & $1.781(1.261,2.364)$ \\
\hline
\end{tabular}


991 Table 4. Median recruitment at unfished equilibrium, $R_{0}$, (fish $\cdot \mathrm{ha}^{-1}$ ) of northern Wisconsin

992 walleye (Sander vitreus) under alternative assumptions of prior distributions for $\alpha, \beta$ and $\sigma$, and

993 average pairwise Geweke's (1992) $Z$-scores for $R_{0}$ to test for similarity in $R_{0}$ estimates among

994 models; at the bottom are average Geweke's (1992) Z-scores for $\alpha, \beta$, and $\sigma$ to test for similarity

995 of the first $10 \%$ and the last $50 \%$ of MCMC samples within a given model, including DIC

996 values.

\begin{tabular}{|c|c|c|c|c|c|}
\hline \multirow[t]{2}{*}{ Lake } & \multicolumn{4}{|c|}{$R_{0}$} & \multirow[t]{2}{*}{$R_{0} Z$-score } \\
\hline & LNN-InvG & LNLN-InvG & LNN & LNLN & \\
\hline Regional & 20.147 & 20.907 & 22.143 & 23.211 & 1.334 \\
\hline Butternut (Forest) & 20.071 & 20.241 & 21.460 & 22.241 & 1.964 \\
\hline Franklin & 13.374 & 13.269 & 15.523 & 15.869 & 1.386 \\
\hline Bearskin & 25.672 & 25.689 & 25.204 & 25.151 & 0.356 \\
\hline Squirrel & 21.115 & 21.412 & 21.655 & 21.853 & 0.118 \\
\hline Big Arbor Vitae & 13.633 & 13.585 & 14.279 & 13.804 & 0.044 \\
\hline Pelican & 7.851 & 7.122 & 10.120 & 9.715 & 0.043 \\
\hline Big St Germain & 15.244 & 15.431 & 18.029 & 18.805 & 0.595 \\
\hline Plum & 31.631 & 32.965 & 35.037 & 36.702 & 1.949 \\
\hline Star & 25.808 & 26.514 & 26.507 & 27.243 & 1.032 \\
\hline North Twin & 17.614 & 18.119 & 16.435 & 16.854 & 0.772 \\
\hline Lac Vieux Desert & 6.728 & 6.356 & 12.586 & 12.606 & 2.264 \\
\hline Sherman & 51.004 & 52.008 & 51.524 & 52.609 & 1.206 \\
\hline Squaw & 5.208 & 5.076 & 4.748 & 4.466 & 1.695 \\
\hline Butternut (Price) & 16.489 & 16.844 & 17.951 & 18.450 & 1.664 \\
\hline Wolf & 14.702 & 14.899 & 16.421 & 16.868 & 1.907 \\
\hline Big Crooked & 12.424 & 12.462 & 14.151 & 14.389 & 1.110 \\
\hline Escanaba & 70.714 & 70.060 & 71.633 & 71.183 & 1.437 \\
\hline Grindstone & 39.135 & 40.927 & 39.558 & 41.493 & 0.697 \\
\hline Round & 24.701 & 25.944 & 26.776 & 28.258 & 1.916 \\
\hline Bass Patterson & 17.033 & 16.360 & 17.501 & 16.994 & 0.919 \\
\hline Lower Eau Claire & 16.753 & 17.336 & 18.925 & 19.705 & 0.829 \\
\hline Middle Eau Claire & 50.831 & 51.001 & 54.661 & 54.298 & 0.000 \\
\hline Siskiwit & 6.318 & 6.073 & 5.652 & 5.275 & 1.586 \\
\hline Pine & 7.488 & 6.959 & 9.511 & 8.949 & 1.406 \\
\hline Annabelle & 3.441 & 3.167 & 2.991 & 2.363 & 0.353 \\
\hline$\alpha Z$-score & 1.214 & 0.876 & 1.048 & 1.011 & \\
\hline$\beta Z$-score & 0.623 & 0.506 & 0.679 & 0.242 & \\
\hline$\sigma Z$-score & 0.642 & 0.978 & 1.040 & 1.317 & \\
\hline DIC & 1356.103 & 1383.967 & 1378.196 & 1385.128 & \\
\hline
\end{tabular}


998 Table 5. Highest posterior density (HPD) estimates and lower and upper 95\% Bayesian credible 999 limits of regional and lake-specific growth parameters for northern Wisconsin walleye (Sander 1000 vitreus).

\begin{tabular}{llll}
\hline Lake & $L_{\infty}(\mathrm{cm})$ & $K$ & $t_{0}$ \\
\hline Regional & $68.61(64.31,73.41)$ & $0.13(0.11,0.15)$ & $-1.23(-1.43,-1.02)$ \\
Butternut (Forest) & $63.93(59.03,68.81)$ & $0.15(0.13,0.18)$ & $-0.91(-1.13,-0.71)$ \\
Franklin & $74.85(69.60,80.14)$ & $0.14(0.12,0.16)$ & $-0.54(-0.66,-0.41)$ \\
Bearskin & $70.00(64.03,76.76)$ & $0.13(0.10,0.15)$ & $-1.20(-1.42,-0.98)$ \\
Squirrel & $76.63(68.20,86.61)$ & $0.10(0.08,0.11)$ & $-1.31(-1.53,-1.11)$ \\
Big Arbor Vitae & $84.71(74.19,96.67)$ & $0.09(0.07,0.11)$ & $-1.67(-1.97,-1.42)$ \\
Pelican & $70.23(64.57,75.82)$ & $0.13(0.11,0.15)$ & $-1.05(-1.22,-0.87)$ \\
Big St Germain & $85.52(76.10,95.30)$ & $0.10(0.08,0.11)$ & $-0.85(-1.01,-0.69)$ \\
Plum & $68.58(63.27,73.84)$ & $0.14(0.12,0.16)$ & $-0.89(-1.07,-0.71)$ \\
Star & $79.07(69.72,89.10)$ & $0.09(0.07,0.11)$ & $-1.95(-2.21,-1.66)$ \\
North Twin & $81.69(72.42,91.54)$ & $0.10(0.08,0.12)$ & $-1.00(-1.17,-0.80)$ \\
Lac Vieux Desert & $81.38(71.96,91.62)$ & $0.09(0.07,0.11)$ & $-1.66(-1.95,-1.43)$ \\
Sherman & $62.33(57.48,67.44)$ & $0.14(0.12,0.17)$ & $-1.25(-1.48,-0.97)$ \\
Squaw & $58.29(53.85,62.51)$ & $0.14(0.12,0.16)$ & $-1.15(-1.36,-0.94)$ \\
Butternut (Price) & $75.84(67.49,85.65)$ & $0.10(0.08,0.12)$ & $-1.29(-1.52,-1.06)$ \\
Wolf & $60.91(57.99,63.30)$ & $0.22(0.19,0.25)$ & $-0.94(-1.13,-0.74)$ \\
Big Crooked & $60.99(58.50,63.47)$ & $0.22(0.19,0.25)$ & $-0.94(-1.15,-0.77)$ \\
Escanaba & $78.92(71.55,87.15)$ & $0.10(0.08,0.11)$ & $-2.02(-2.28,-1.76)$ \\
Grindstone & $65.10(61.95,68.88)$ & $0.17(0.15,0.19)$ & $-0.93(-1.10,-0.75)$ \\
Round & $54.74(52.58,57.40)$ & $0.22(0.20,0.25)$ & $-0.45(-0.59,-0.31)$ \\
Bass Patterson & $64.03(58.39,70.00)$ & $0.13(0.10,0.15)$ & $-1.78(-2.09,-1.48)$ \\
Lower Eau Claire & $58.55(55.91,61.01)$ & $0.21(0.18,0.23)$ & $-0.87(-1.05,-0.70)$ \\
Middle Eau Claire & $61.85(57.33,66.88)$ & $0.15(0.12,0.18)$ & $-1.61(-1.91,-1.29)$ \\
Siskiwit & $47.63(46.25,49.07)$ & $0.24(0.22,0.27)$ & $-0.99(-1.16,-0.83)$ \\
Pine & $77.47(67.92,87.96)$ & $0.09(0.07,0.10)$ & $-1.75(-2.03,-1.49)$ \\
Annabelle & $68.05(61.14,74.63)$ & $0.10(0.08,0.12)$ & $-1.81(-2.08,-1.53)$ \\
\hline & & &
\end{tabular}


1002 Table 6. Highest posterior density (HPD) estimates and lower and upper 95\% Bayesian credible

1003 limits of regional and lake-specific natural mortality and the parameters of the logistic

1004 maturity/spearing selectivity function for northern Wisconsin walleye (Sander vitreus).

\begin{tabular}{llll}
\hline Lake & $h$ & $m$ & $M$ \\
\hline Regional & $4.80(3.45,6.22)$ & $3.36(3.13,3.63)$ & $0.24(0.17,0.35)$ \\
Butternut (Forest) & $6.80(3.55,11.98)$ & $3.10(3.07,3.13)$ & $0.25(0.23,0.27)$ \\
Franklin & $7.68(1.75,18.01)$ & $2.81(2.56,3.04)$ & $0.12(0.08,0.16)$ \\
Bearskin & $6.66(4.00,11.44)$ & $3.09(3.02,3.15)$ & $0.50(0.46,0.54)$ \\
Squirrel & $6.76(1.11,13.11)$ & $3.13(3.08,3.18)$ & $0.42(0.4,0.45)$ \\
Big Arbor Vitae & $5.23(3.72,7.69)$ & $3.34(3.16,3.54)$ & $0.51(0.45,0.56)$ \\
Pelican & $2.67(2.26,3.10)$ & $4.17(3.96,4.38)$ & $0.17(0.12,0.22)$ \\
Big St Germain & $2.64(2.32,3.08)$ & $4.34(4.14,4.55)$ & $0.02(0.00,0.05)$ \\
Plum & $5.12(2.49,7.90)$ & $3.16(3.09,3.24)$ & $0.15(0.11,0.19)$ \\
Star & $2.08(1.88,2.36)$ & $4.03(3.67,4.38)$ & $0.40(0.30,0.51)$ \\
North Twin & $4.18(3.38,5.18)$ & $3.50(3.25,3.74)$ & $0.73(0.62,0.87)$ \\
Lac Vieux Desert & $2.37(2.13,2.62)$ & $4.68(4.46,4.90)$ & $0.29(0.23,0.35)$ \\
Sherman & $7.88(2.19,19.49)$ & $2.88(2.62,3.07)$ & $0.23(0.2,0.27)$ \\
Squaw & $4.52(4.30,4.77)$ & $3.29(3.12,3.45)$ & $0.60(0.54,0.66)$ \\
Butternut (Price) & $5.50(3.26,8.11)$ & $3.13(3.07,3.22)$ & $0.28(0.24,0.33)$ \\
Wolf & $5.71(3.01,10.00)$ & $3.12(3.03,3.20)$ & $0.02(0.00,0.04)$ \\
Big Crooked & $5.75(2.69,10.24)$ & $3.10(3.02,3.18)$ & $0.02(0.00,0.05)$ \\
Escanaba & $11.81(7.61,19.64)$ & $2.69(2.67,2.72)$ & $0.79(0.75,0.83)$ \\
Grindstone & $5.85(3.26,9.64)$ & $3.12(3.05,3.20)$ & $0.25(0.20,0.30)$ \\
Round & $4.39(2.53,6.82)$ & $3.31(3.18,3.47)$ & $0.23(0.18,0.29)$ \\
Bass Patterson & $2.33(2.20,2.48)$ & $4.05(3.92,4.18)$ & $0.57(0.53,0.63)$ \\
Lower Eau Claire & $3.10(0.83,5.95)$ & $3.44(3.32,3.59)$ & $0.19(0.14,0.23)$ \\
Middle Eau Claire & $4.36(1.97,7.10)$ & $3.26(3.16,3.39)$ & $0.23(0.19,0.27)$ \\
Siskiwit & $2.30(2.10,2.48)$ & $4.41(4.19,4.64)$ & $0.39(0.34,0.46)$ \\
Pine & $7.14(4.76,10.25)$ & $2.85(2.76,2.93)$ & $0.67(0.59,0.75)$ \\
Annabelle & $5.20(3.11,7.69)$ & $3.21(3.08,3.36)$ & $0.58(0.53,0.65)$ \\
\hline & & &
\end{tabular}

1005

1006 
1007 Table 7. Median adult walleye (Sander vitreus) densities at unfished equilibrium $(D)\left(\right.$ fish $\left.^{\prime} \mathrm{ha}^{-1}\right)$

1008 and probabilities of population collapse for the selected 25 lakes under various exploitation rates

1009 (divided equally between recreational and tribal fisheries), assuming a 38-cm minimum length

1010 limit for the recreational fishery.

\begin{tabular}{|c|c|c|c|c|c|}
\hline Lake & $D$ & $u=0.20$ & $u=0.35$ & $u=0.50$ & $u=0.65$ \\
\hline Regional & 23.28 & 0.03 & 0.24 & 0.55 & 0.60 \\
\hline Butternut (Forest) & 26.44 & 0.01 & 0.06 & 0.11 & 0.20 \\
\hline Franklin & 29.16 & 0.03 & 0.23 & 0.41 & 0.47 \\
\hline Bearskin & 20.19 & 0.05 & 0.15 & 0.22 & 0.30 \\
\hline Squirrel & 18.48 & 0.02 & 0.11 & 0.20 & 0.31 \\
\hline Big Arbor Vitae & 11.49 & 0.11 & 0.33 & 0.44 & 0.54 \\
\hline Pelican & 14.68 & 0.42 & 0.70 & 0.85 & 0.93 \\
\hline Big St Germain & 40.67 & 0.05 & 0.43 & 0.76 & 0.90 \\
\hline Plum & 43.59 & 0.01 & 0.05 & 0.11 & 0.16 \\
\hline Star & 17.57 & 0.06 & 0.20 & 0.35 & 0.40 \\
\hline North Twin & 14.08 & 0.03 & 0.06 & 0.13 & 0.16 \\
\hline Lac Vieux Desert & 17.94 & 0.26 & 0.46 & 0.53 & 0.60 \\
\hline Sherman & 52.93 & 0.00 & 0.00 & 0.00 & 0.01 \\
\hline Squaw & 8.01 & 0.62 & 0.78 & 0.83 & 0.85 \\
\hline Butternut (Price) & 19.35 & 0.10 & 0.24 & 0.35 & 0.41 \\
\hline Wolf & 42.85 & 0.03 & 0.31 & 0.64 & 0.85 \\
\hline Big Crooked & 38.45 & 0.03 & 0.50 & 0.83 & 0.90 \\
\hline Escanaba & 45.10 & 0.00 & 0.01 & 0.01 & 0.01 \\
\hline Grindstone & 38.25 & 0.01 & 0.06 & 0.08 & 0.12 \\
\hline Round & 30.84 & 0.02 & 0.12 & 0.31 & 0.40 \\
\hline Bass Patterson & 11.29 & 0.12 & 0.25 & 0.39 & 0.58 \\
\hline Lower Eau Claire & 24.61 & 0.08 & 0.42 & 0.70 & 0.80 \\
\hline Middle Eau Claire & 46.88 & 0.00 & 0.00 & 0.02 & 0.07 \\
\hline Siskiwit & 8.99 & 0.66 & 0.81 & 0.84 & 0.86 \\
\hline Pine & 11.12 & 0.07 & 0.16 & 0.20 & 0.30 \\
\hline Annabelle & 4.99 & 0.38 & 0.46 & 0.61 & 0.70 \\
\hline
\end{tabular}

1011 


\section{Figure captions}

1013 Fig. 1. Map showing Wisconsin counties with the Ceded Territory of Wisconsin shaded in gray.

1014

1015 Fig. 2. Schematic diagram for the age-structured integrated analysis (Maunder 2003) of growth,

1016 natural mortality, selectivity, and maturity of walleye (Sander vitreus) populations in northern

1017 Wisconsin lakes; $i$ represents lake and $a$ represents age; the six parameters estimated by the

1018 model as random effects are indicated in boldface, known model inputs are represented by ovals,

1019 and observed data (i.e., length-at-age data and age composition of adult PEs) to which predicted

1020 values are fit through optimization (optim) are represented by rounded squares. Remaining

1021 symbols are defined in the Methods section.

1022

1023 Fig. 3. Stock-recruitment relationships fit to age-0 and adult walleye (Sander vitreus) abundance

1024 data from the selected 25 northern Wisconsin lakes based on the hierarchical Bayesian meta-

1025 analysis with LNN-InvG priors (continuous lines) and lake-by-lake analyses (broken lines).

1026

1027 Fig. 4. Predicted age compositions of adult population estimates based on the hierarchical

1028 Bayesian model (lines) fit to observed data (symbols) of age compositions of adult population

1029 estimates (PEs) (from mark-recapture surveys) of walleye (Sander vitreus) populations from the

1030 selected 25 northern Wisconsin lakes.

1031

1032 Fig. 5. Proportions (median and interquartile range) of initial walleye (Sander vitreus) adult

1033 abundance remaining after 100 years ( $a$ and $b$ ) and corresponding long-term sustainable

1034 recreational and spearing harvest (fish $\left.\cdot \mathrm{ha}^{-1}\right)(\mathrm{c}$ and $\mathrm{d})$ under various exploitation rates using 
1035 regional parameter estimates, assuming a logistic selectivity curve for the spearing fishery and a

1036 38-cm minimum length limit for the recreational fishery (a and c); and a logistic selectivity curve

1037 for the spearing and recreational fisheries (i.e., no minimum length limit for the recreational

1038 fishery) ( $\mathrm{b}$ and $\mathrm{d}$ ). Proportions of adults remaining were calculated by dividing final abundance

1039 (i.e., year 100) by the initial (i.e., year 1), assumed to be at an unfished equilibrium. Values in

1040 parentheses are proportions of collapse associated with the respective exploitation rates.

1041

1042 Fig. 6. Contour plots of performances of northern Wisconsin walleye (Sander vitreus) fisheries

1043 under different combinations of recreational and tribal exploitation rates (0-25\%) and a 38-cm

1044 minimum length limit for the recreational fishery using regional parameter estimates. Plots

1045 display median (a) predicted proportion of adult abundance remaining after 100 years and (b)

1046 combined long-term recreational and tribal harvest $\left(\right.$ fish $\left.\cdot \mathrm{ha}^{-1}\right)$.

1047

1048 Fig. 7. Regional model trajectories (median and interquartile range) of northern Wisconsin adult

1049 walleye (Sander vitreus) abundance and harvest under a 35\% exploitation rate (17.5\%

1050 recreational and $17.5 \%$ spearing), assuming a $38-\mathrm{cm}$ minimum length limit for the recreational

1051 fishery. 

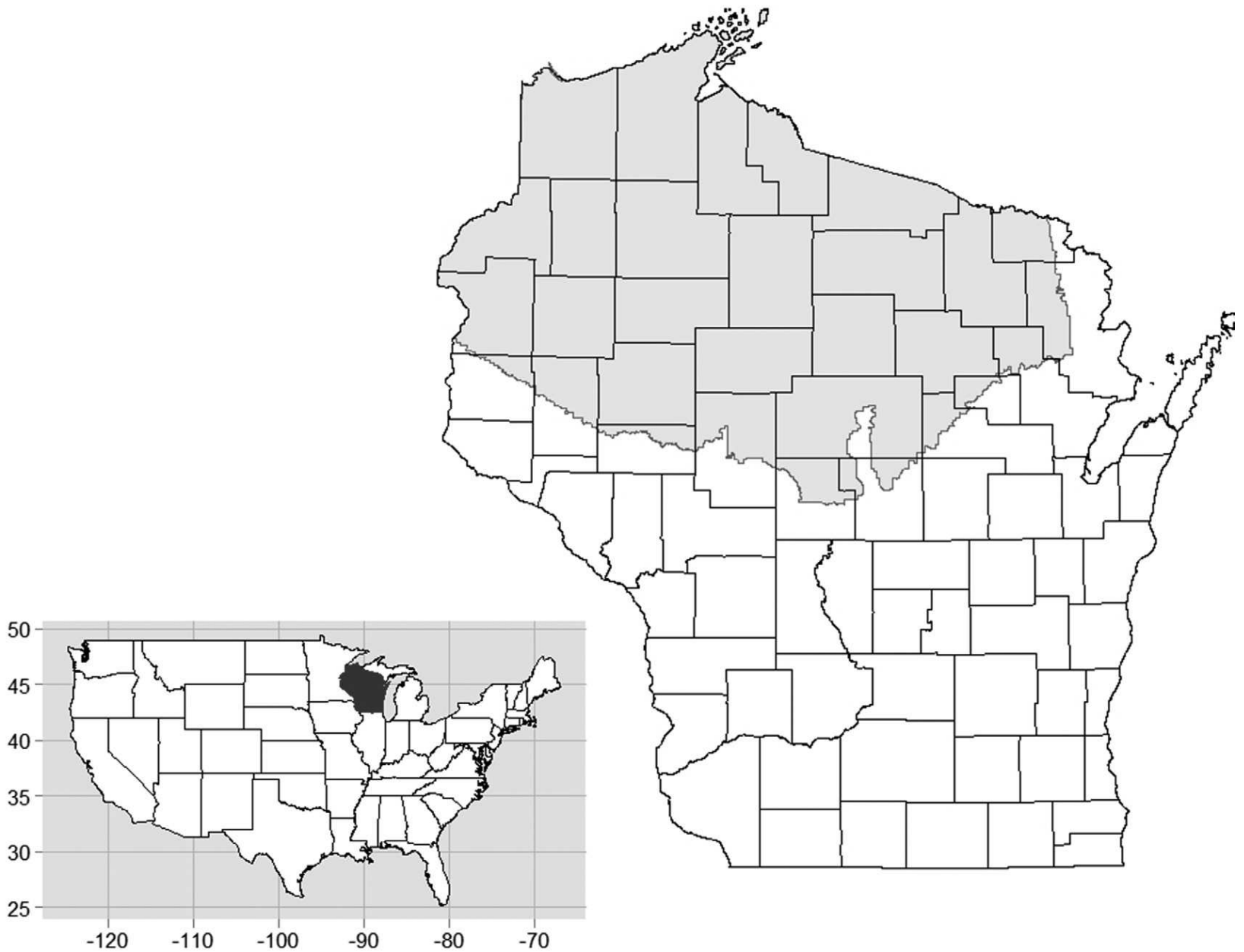

1053 Fig. 1. 


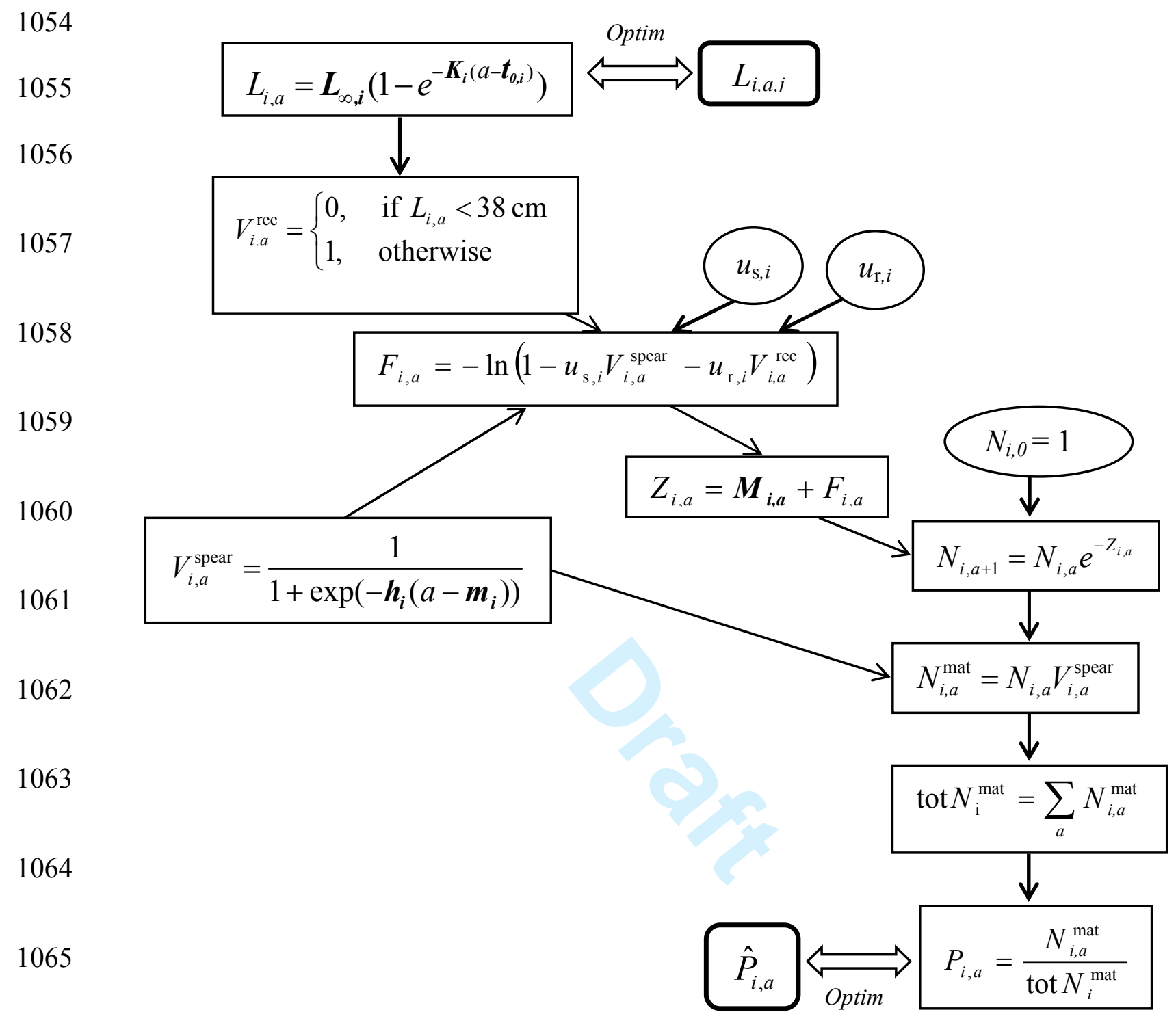

1066

1067 Fig. 2. 

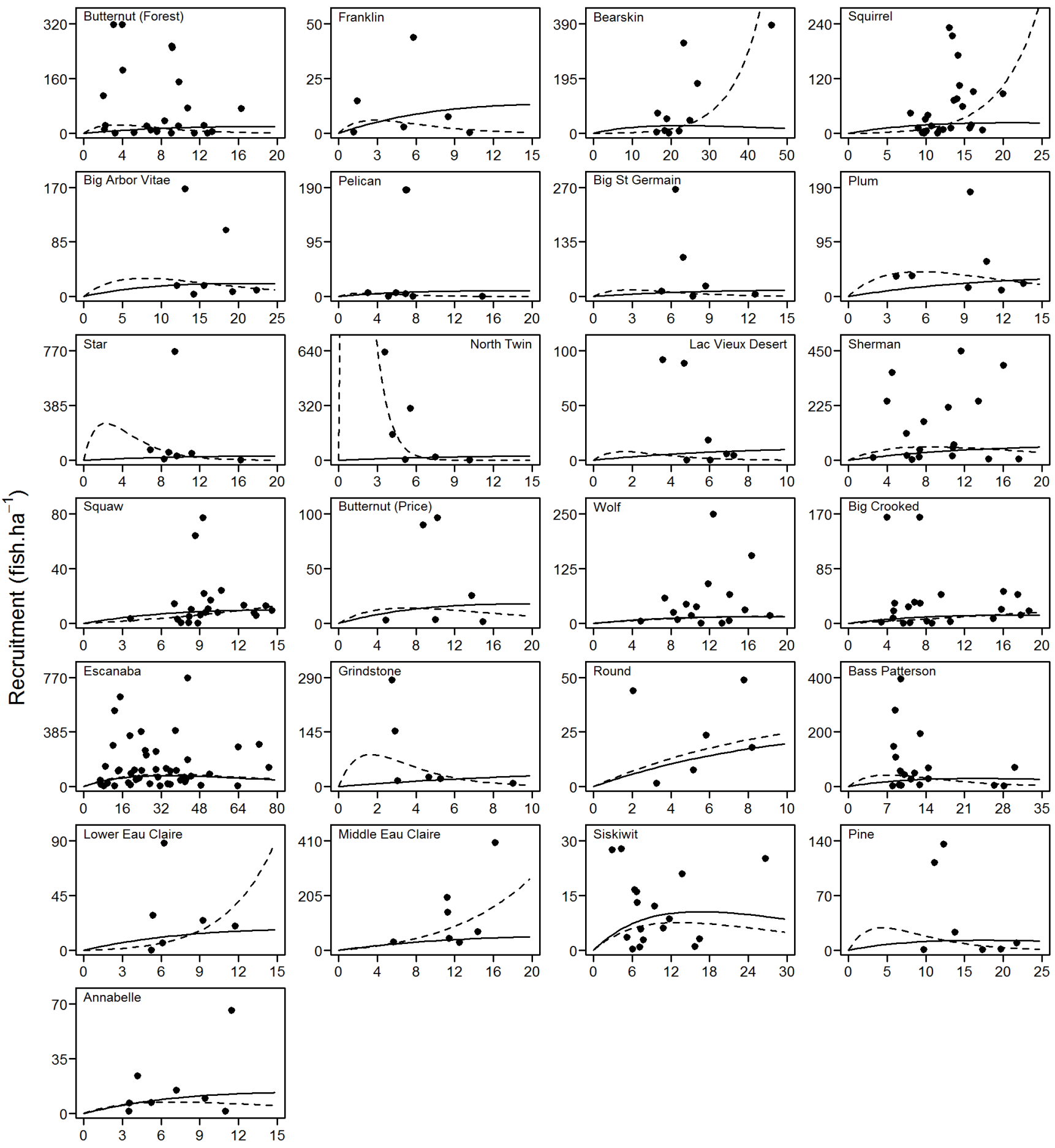

1068

Spawning stock (fish.ha ${ }^{-1}$ )

Fig. 3. 

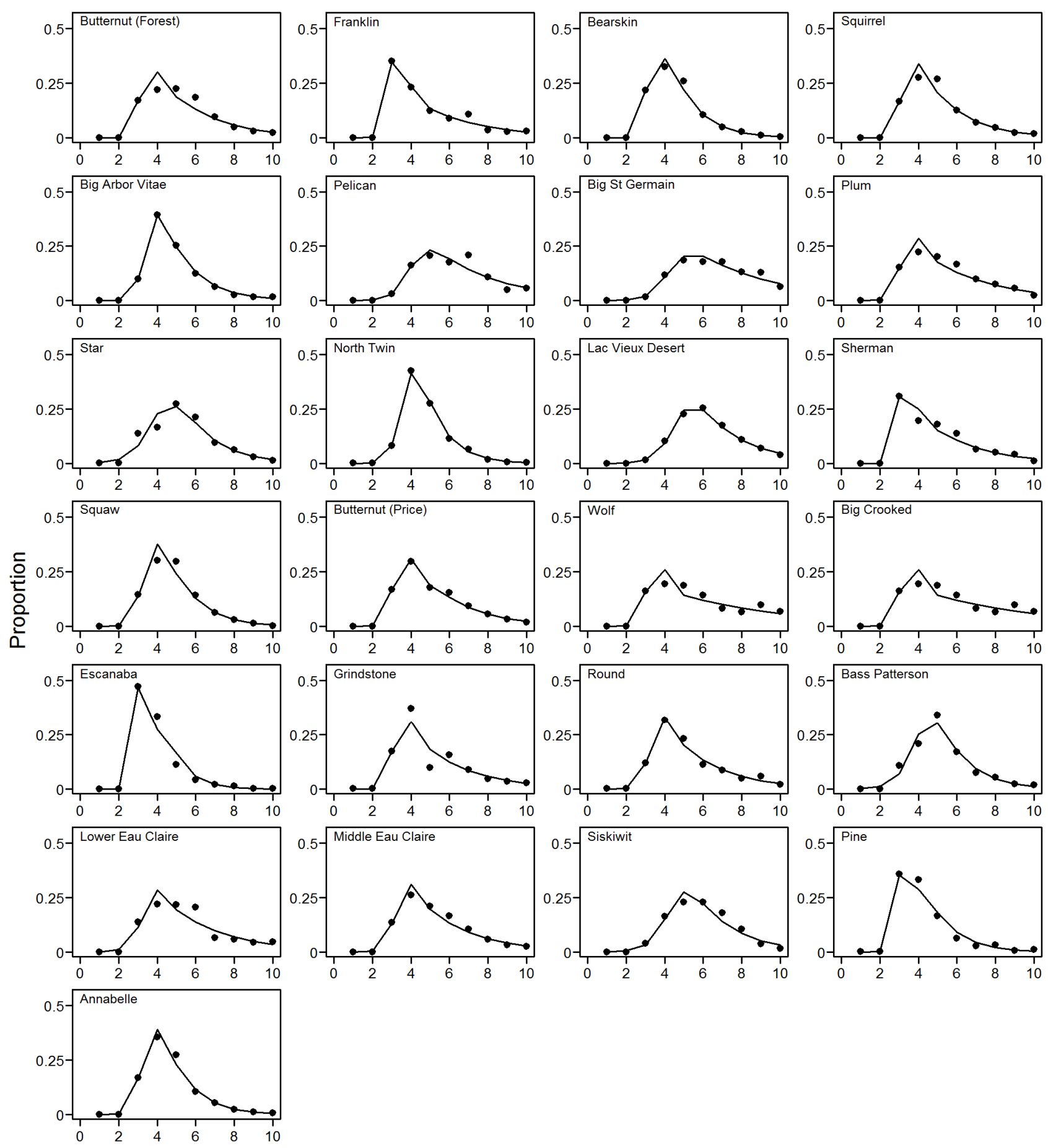

1070

Age

$1071 \quad$ Fig. 4. 

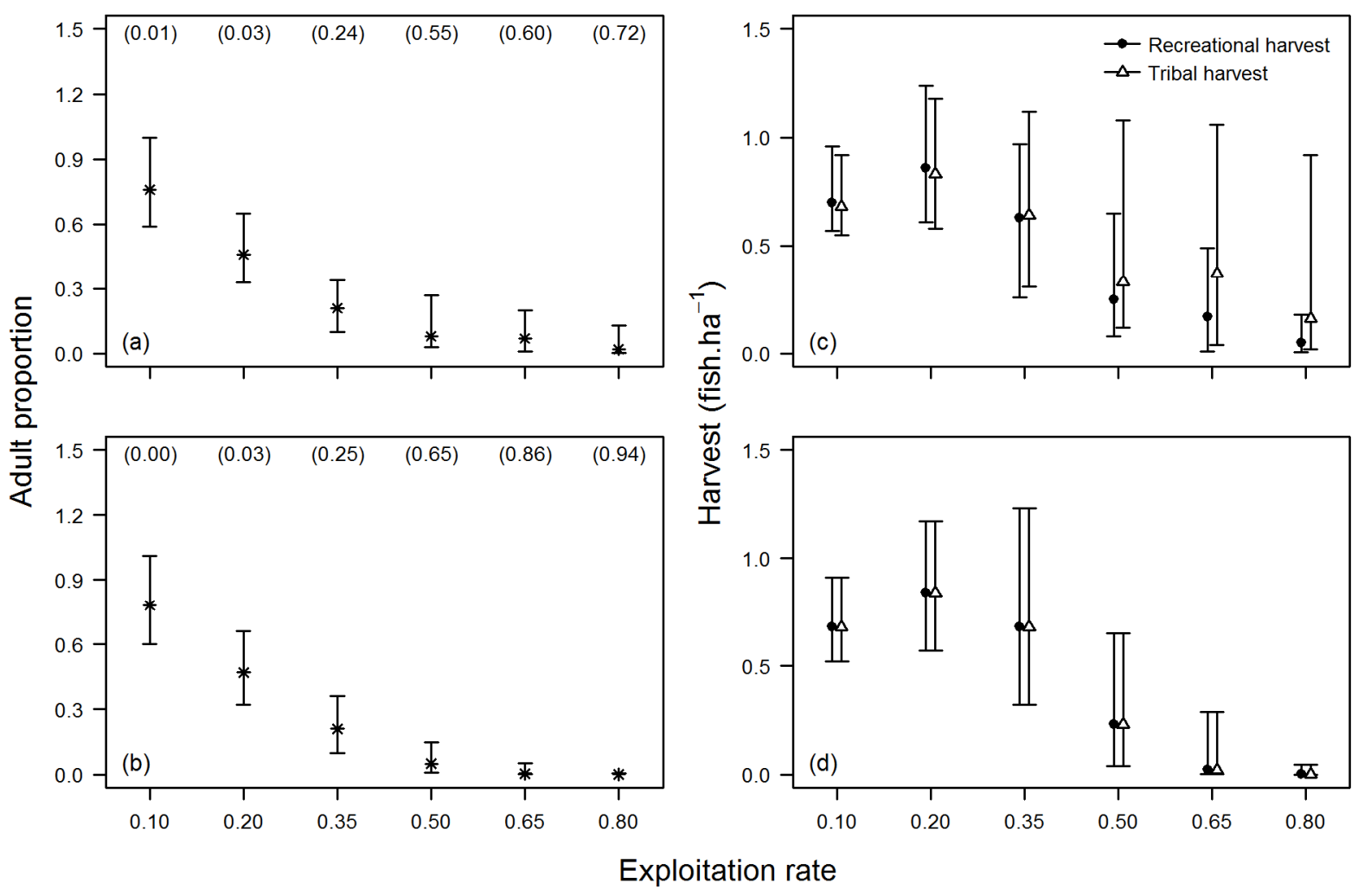

1072

1073 Fig. 5. 


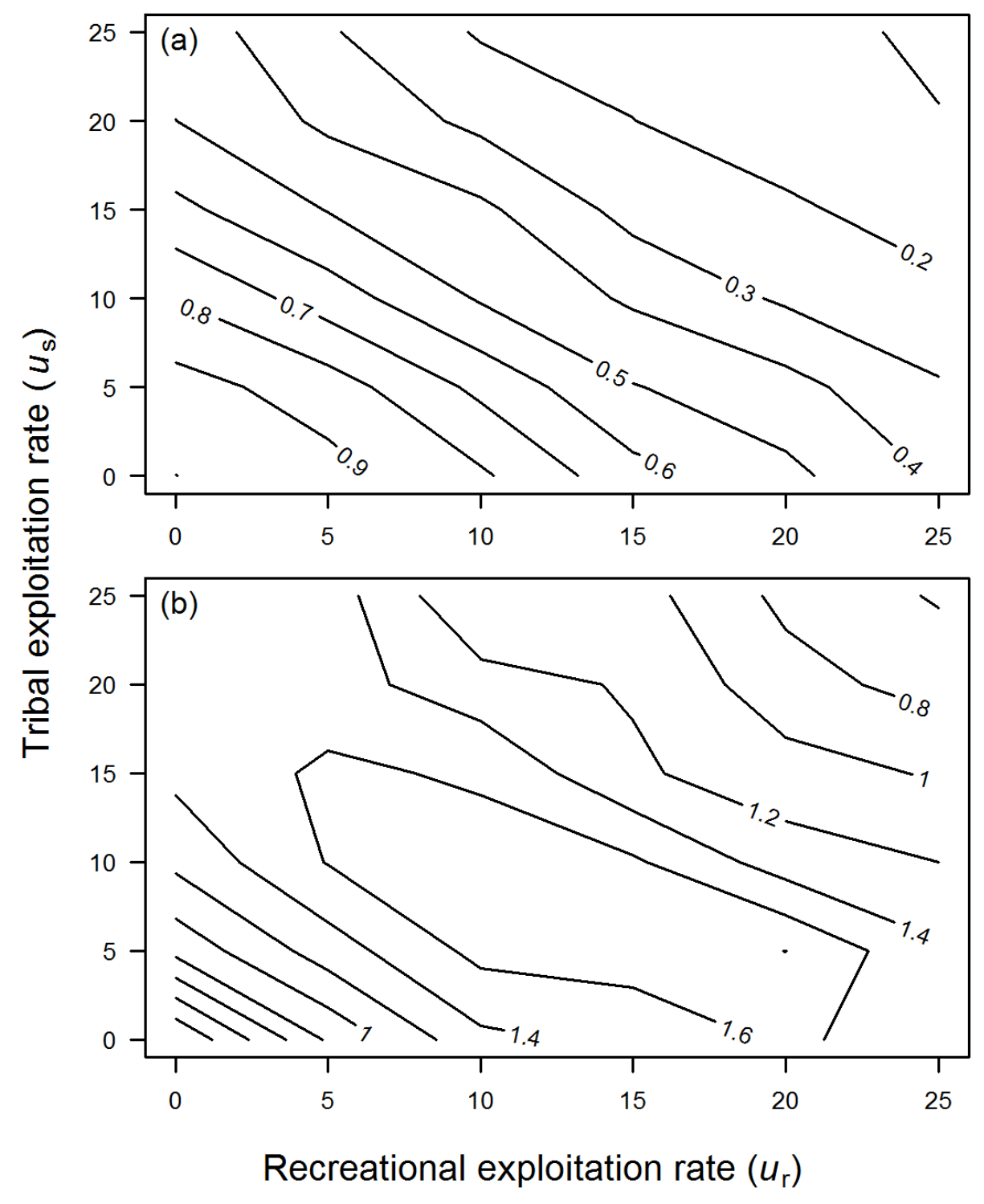

1074

1075 Fig. 6. 

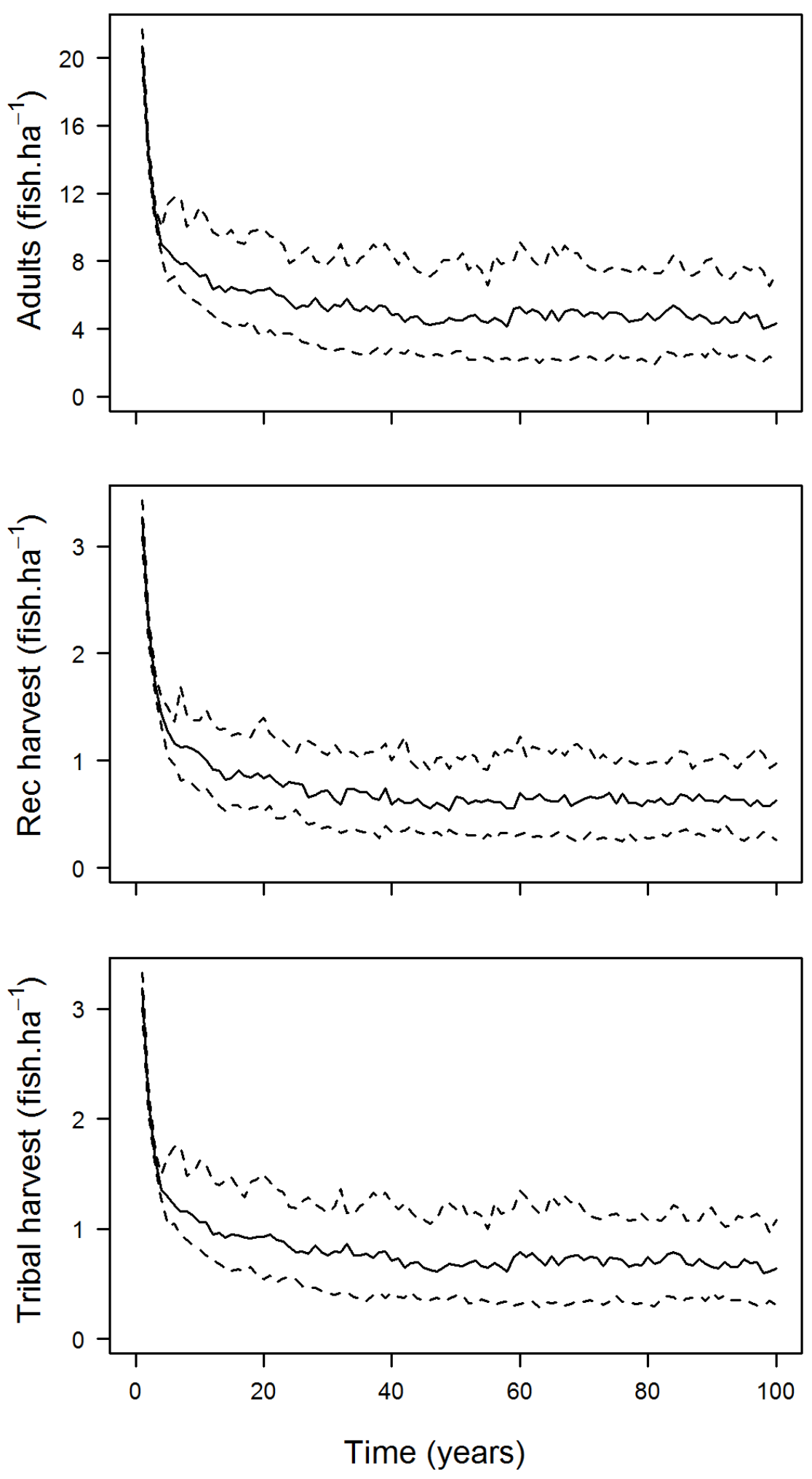

$1077 \quad$ Fig. 7. 


\section{Appendix}

1079 Table A1: Highest posterior density (HPD) estimates of regional and lake-specific Ricker stock-

1080 recruitment parameters $(\alpha, \beta, \sigma)$ for northern Wisconsin walleye (Sander vitreus) under

1081 alternative assumptions of prior distributions (see Table 3 for LNN-InvG model estimates).

1082

\begin{tabular}{llll}
\hline Lake & LNLN-InvG & LNN & LNLN \\
\hline Regional & $2.751,0.047,1.965$ & $2.831,0.046,2.113$ & $2.799,0.043,2.114$ \\
Butternut (Forest) & $2.681,0.047,2.401$ & $2.753,0.046,2.852$ & $2.710,0.044,2.852$ \\
Franklin & $2.033,0.056,1.882$ & $2.169,0.051,2.052$ & $2.131,0.049,2.051$ \\
Bearskin & $3.209,0.042,1.978$ & $3.192,0.043,2.231$ & $3.092,0.041,2.230$ \\
Squirrel & $2.918,0.045,1.811$ & $2.941,0.045,1.769$ & $2.859,0.042,1.769$ \\
Big Arbor Vitae & $2.669,0.047,1.802$ & $2.700,0.047,1.689$ & $2.629,0.045,1.686$ \\
Pelican & $1.602,0.066,2.201$ & $1.971,0.053,2.872$ & $1.920,0.052,2.861$ \\
Big St Germain & $2.264,0.053,2.253$ & $2.492,0.049,3.004$ & $2.461,0.046,3.000$ \\
Plum & $3.651,0.039,1.757$ & $3.909,0.039,1.512$ & $3.838,0.036,1.521$ \\
Star & $3.482,0.040,1.859$ & $3.512,0.041,1.957$ & $3.449,0.038,1.962$ \\
North Twin & $3.219,0.042,2.102$ & $3.152,0.043,2.677$ & $3.111,0.040,2.675$ \\
Lac Vieux Desert & $1.762,0.062,2.350$ & $2.148,0.052,3.201$ & $2.112,0.050,3.201$ \\
Sherman & $5.091,0.032,1.840$ & $5.189,0.032,1.860$ & $5.104,0.031,1.863$ \\
Squaw & $1.667,0.064,1.762$ & $1.610,0.058,1.662$ & $1.588,0.058,1.654$ \\
Butternut (Price) & $2.481,0.050,1.837$ & $2.530,0.048,1.869$ & $2.492,0.046,1.882$ \\
Wolf & $2.259,0.053,2.256$ & $2.372,0.049,2.727$ & $2.321,0.047,2.738$ \\
Big Crooked & $1.991,0.057,2.300$ & $2.090,0.052,2.734$ & $2.049,0.051,2.727$ \\
Escanaba & $5.913,0.029,1.612$ & $6.092,0.029,1.431$ & $6.011,0.029,1.431$ \\
Grindstone & $4.109,0.036,1.851$ & $4.111,0.038,1.952$ & $4.054,0.035,1.954$ \\
Round & $3.074,0.043,1.789$ & $3.163,0.043,1.660$ & $3.120,0.040,1.662$ \\
Bass Patterson & $3.391,0.041,1.830$ & $3.460,0.041,1.811$ & $3.382,0.039,1.823$ \\
Lower Eau Claire & $2.452,0.050,1.921$ & $2.538,0.048,2.176$ & $2.501,0.045,2.179$ \\
Middle Eau Claire & $4.810,0.033,1.774$ & $5.400,0.032,1.542$ & $5.209,0.031,1.550$ \\
Siskiwit & $1.741,0.062,1.733$ & $1.671,0.057,1.550$ & $1.642,0.057,1.552$ \\
Pine & $1.971,0.057,1.918$ & $2.100,0.052,2.152$ & $2.041,0.051,2.159$ \\
Annabelle & $2.062,0.056,1.780$ & $2.040,0.053,1.640$ & $2.000,0.051,1.641$ \\
\hline & & & \\
\hline
\end{tabular}

